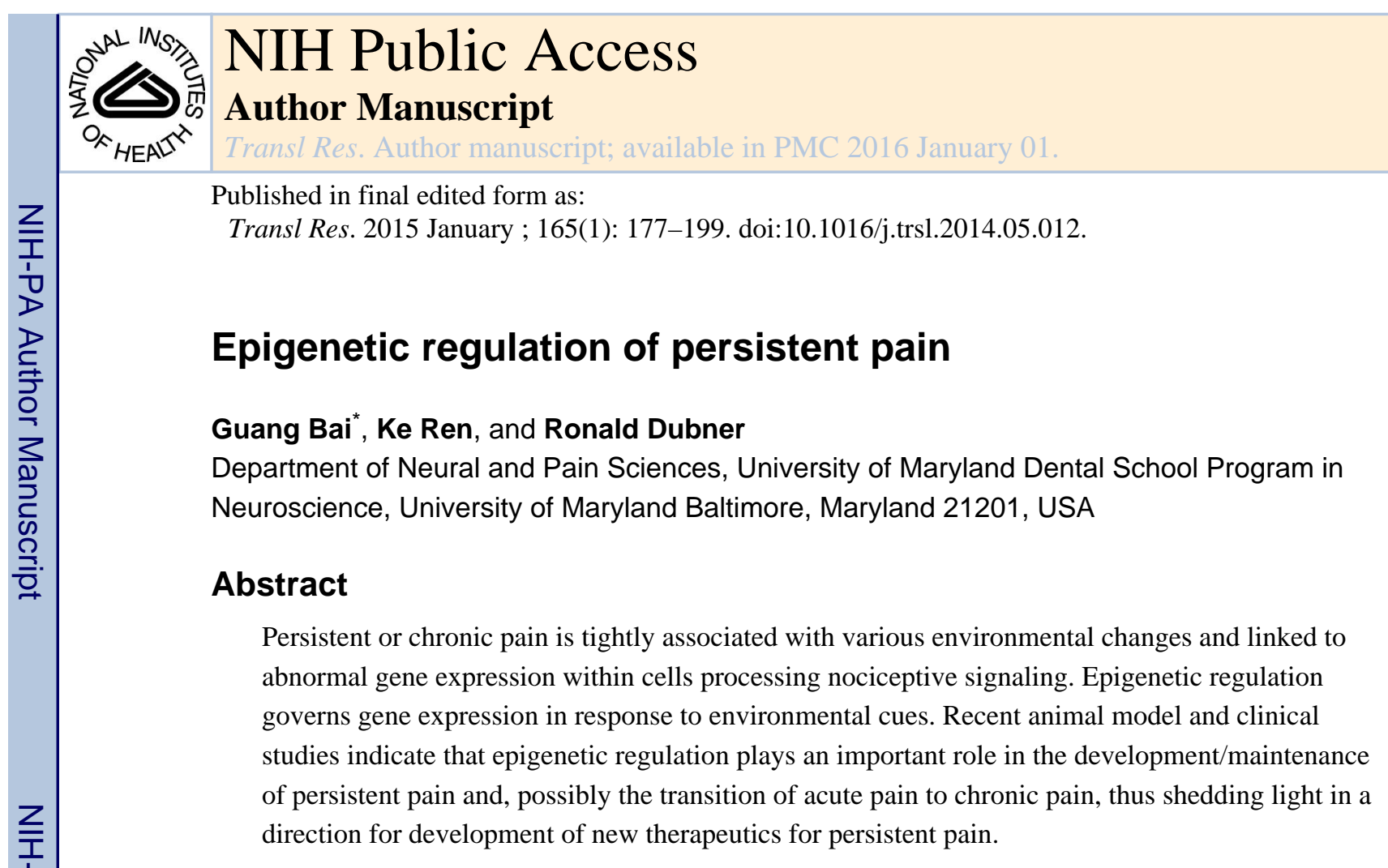

\title{
Introduction
}

Persistent or chronic pain is a complicated clinic condition that impacts the lives of approximately a quarter of the population [1-7]. This clinic condition can be developed from acute pain resulting from tissue damage or be associated with numerous human diseases [7-8]. Similar to varied individual pain sensitivity, there is a large difference in vulnerability of individuals to develop persistent pain [5-10]. Although the mechanisms underlying this variation remain largely unknown, efforts have been spent to look for genetic mechanisms and gene expression.

It has been well established from clinical and laboratory studies that under persistent pain conditions cells processing pain signaling, i.e., nociceptors in the peripheral nervous system and neurons/glia in the central nervous system, become sensitized in response to various stimuli. This increased sensitivity is accompanied by functional and structural changes (plasticity) [7, 11-14]. Multiple molecular mechanisms are likely responsible for these changes. Various chemicals/factors and relevant receptor/signal transduction pathways are proposed to become active during persistent pain [15-16]. Gene-specific and genome-wide association studies (GWAS) further demonstrate that many genes undergo expression changes at mRNA and protein levels in tissues/cells of pain circuitry during the development/maintenance of persistent pain [17-24].

(C) 2014 Mosby, Inc. All rights reserved

*Corresponding Author: Guang Bai gbai@umaryland.edu Phone: 410-706-2082 Fax: 410-706-0865.

Publisher's Disclaimer: This is a PDF file of an unedited manuscript that has been accepted for publication. As a service to our customers we are providing this early version of the manuscript. The manuscript will undergo copyediting, typesetting, and review of the resulting proof before it is published in its final citable form. Please note that during the production process errors may be discovered which could affect the content, and all legal disclaimers that apply to the journal pertain. 
Cases of single nucleotide polymorphisms (SNPs) have been found to be risk factors in the development of persistent pain in humans [25-27]. For example, several missense SNPs in the SCN9A gene increase activity of its protein product voltage-gated sodium Nav1.7 and are associated with primary erythromelalgia, paroxysmal extreme pain disorder and osteoarthritic pain [26-27]. In addition to the genetic mechanism that determines and regulates gene expression based on genomic DNA sequences, recently, DNA-sequence independent mechanisms in regulating gene expression, namely epigenetic regulation, have been proposed [28-34]. Primarily, epigenetic mechanisms are involved in gene regulation during early development, in X-chromosome inactivation and in response to various environmental changes. Epigenetic regulation has been found to participate in many physiological and pathological processes, such as neuronal plasticity and cancer, in which various environmental factors are involved and sometimes, however, no cell division occurs [28-29, 35-37]. In most of these cases, genetic mechanisms fail to explain the changes. Environmental factors such as stress, tissues damage and disease conditions largely impact the vulnerability of individuals to develop persistent pain clearly via DNA sequenceindependent mechanism(s). This concept is supported by several lines of evidence. Tissue damage or inflammation is a common environmental event seen in many types of persistent pain. For example, we observed that rats experiencing stimulation by the inflammatory irritant carrageenan to the hindpaw at the first postnatal week exhibited more intense responses when challenged by the same irritant at a young adult age (day 60) [38]. Interestingly, mice dams fed with high methyl donor diets during the perinatal period had their male offspring displaying increased mechanical allodynia following skin incision [39]. A number of twin studies have demonstrated the great impact of environmental factors on the development of various pain conditions [40-42]. For example, a study of 33,794 twins indicated that the genetic impact on neck pain development in monozygotic twins diminished following the age when environmental factors become dominant [40]. Environmental factors were involved in inter-personal differences of pain sensitivity and opioid effects [41]. Drug addiction and smoking were associated with epigenetic changes in the nervous system and were found to impact chronic pain [43]. Female smokers reported more chronic pain conditions than non smokers [44]. Heroin addicts developed hyperalgesia [45]. It should be also noticed that many diseases involved in epigenetic regulation are associated with persistent pain, such as cancer [32,46-47] and diabetes [2, 48]. In those diseases, epigenetic factors may indirectly contribute to the development of persistent pain.

The field of study of epigenetic mechanisms underlying pain or persistent pain has been progressing very rapidly in recent years as reviewed by others [10, 13, 49-54]. Currently three major molecular mechanisms have been proposed for epigenetic regulation, i.e., DNA methylation, chromatin remodeling and non-coding RNA (ncRNA) [33, 55-56] even though RNA/DNA editing has been proposed as the fourth mechanism [57]. In this review, we'll summarize and comment on studies on persistent pain related to these three major aspects.

\section{DNA methylation}

DNA methylation is the prototype of epigenetic regulation and, in mammalian genomes, occurs mostly on carbon 5 of the pyrimidine ring of the cytosine residue followed by guanine residue, namely $\mathrm{CpG}$ dinucleotide [58-59]. In mammalian cells, enzymes to 
catalyze this reaction are DNA methyltransferase (DNMT) $1,3 a$ and $3 b$ [60]. In most cases, DNMT1 maintains basic methylation while DNMT3a and $3 \mathrm{~b}$ are responsible for de novo DNA methylation established during the development and induced by various factors [6061]. These enzymes do not show obvious tissue specificity, but their expression is regulated. Methylated CpGs are thought to recruit several nuclear proteins known as methylated $\mathrm{CpG}$ binding proteins (MBDs), but repel other transcription factors [37, 60-62]. Binding of these proteins may recruit inhibitory transcription factors and produce downregulation or silence of gene transcription [37].

Functionally, DNA methylation is a complex event due to the nature of CpGs that are unevenly distributed in the genome and differentially methylated among tissues to form the so-called differentially methylated region (DMR) [43, 63-64]. Following evolution, mammalian genomes have developed small GC-rich regions (less than $1 \mathrm{~kb}$ in most cases) that contain clusters of CpGs and are named CpG islands (CGIs) [65]. Although the precise definition of a CGI is still in debate, this structure often (about half of the total CGIs) appears near (upstream, overlapping or downstream) transcription start sites (TSS) of about $72 \sim 76 \%$ of protein encoding genes in humans [66-70]. It was estimated from genome projects that there are close to 29,000 CGIs in human non-repetitive sequences in which most protein-encoding genes reside [71-72]. Interestingly, a smaller number $(21,377)$ of CGI-like sequences were found in repetitive sequences of humans even though no other protein coding genes except retrotransposons are found in these regions [72]. Sporadic CpGs located within $2 \mathrm{~kb}$ sequences distal to CGIs are termed CGI shore and are responsible for most (more than 70\%) tissue- (among human brain, liver and spleen) and cancer-specific DMRs [73]. Due to the nature of CpGs and the means to estimate/evaluate them, there is confusion in the understanding of this structure [74]. Several important issues should be paid attention to before examining and interpreting the data. First, CpGs are distributed within CGIs, CGI shore, repetitive sequences and intergenic sequences, even though only about $16 \%$ of human CpGs are found in CGIs [75]. Second, in mature or well-differentiated cells CpGs in most CGIs are unmethylated $[61,76]$ and only about 5 8\% CGIs have methylated CpGs to form tissue specific DMRs, most of which are intragenic or intergenic CGIs [70, 77-78]. In response to environmental or intrinsic cues, CpGs in CGI, CGI shore, and non$\mathrm{CGI} / \mathrm{CpG}$ poor promoters can be methylated in a cell or tissue specific manner [34, 79] although approximately $80 \%$ of non-CGI CpGs are methylated in differentiated cells [61, $70,76]$. Third, it is known from promoter reporter studies that the methylation level required to modify transcription varies with promoters and often methylation of a few of CpGs is sufficient, which, however, has not been well illustrated experimentally for most promoters [80]. Lastly, many technologies have been developed to examine methylated CpGs using various approaches, but no single method can efficiently provide all the necessary information to investigators [81-84]. In general, obtaining broader regions with higher resolution of methylation on individual $\mathrm{CpGs}$ consumes more resources and time. Yet a number of laboratories reported evidence showing the involvement of DNA methylation in persistent pain [85-91] (see Table 1 for summary).

Several MBDs participate in regulation of transcription via methylated CpGs [62]. Among these, $\mathrm{MeCP} 2$ has been well studied and linked to neuronal plasticity and several 
neurological disorders including Rett Syndrome, autism and a number of neurological disorders [60, 62, 92-93]. Geranton et al. first analyzed mRNA expression profile of spinal dorsal horn genes in an inflammatory ankle joint pain model in rats and linked a number of genes to be potential targets of MeCP2 [21]. These genes include serum- and glucocorticoidinducible kinase and FK 506 binding protein 5. More importantly, they found MeCP2 phosphorylation increased in spinal lamina I projection neurons after peripheral inflammation. They further demonstrated that complete Freund adjuvant (CFA) induced peripheral inflammation increased $\mathrm{MeCP} 2$ phosphorylation in the spinal cord in a serotonindependent manner [94]. They assumed that phosphorylation relieved MeCP2-related gene repression. However, to clarify whether $\mathrm{MeCP} 2$ works alone or cooperates with methylated CpGs towards proposed genes will be helpful to understand the specificity of such changes. In addition, recently it was reported that active MeCP2 may not only suppress transcription of a set of genes, but also upregulate another set of genes in the nervous system [76]. It is also true for methylated DNA as indicated by recent studies [37]. Very interestingly, examination of CGIs further revealed that MeCP2-upregulated genes were rich in CGIs that, however, were not or lightly methylated, while MeCP2-repressed genes either did not have CGIs or had them heavily methylated [76]. These results indicate that analysis of MeCP2 function should be expanded in both directions of gene expression.

Many genes involved in persistent pain as evidenced by gene-specific and GWAS studies and collected in the Pain Gene Database contain CGI(s), and some of these genes were found to regulate or be regulated by DNA methylation [22]. For example, activation of the CB1 receptor increased total DNA methylation levels in keratinocytes [95] while the OPRM1 promoter of the gene encoding $\mu$-opioid receptor (MOR) was methylated differentially on distinct $\mathrm{CpG}$ clusters between undifferentiated and differentiated neural stem cells and in different regions of the brain [96]. Methylation states relevant to pain conditions have been examined by several laboratories from animals to human. Tajerian et al. provided the first evidence that DNA methylation is indirectly correlated to persistent pain in mouse and human intervertebral discs [85]. They studied the transcriptional downregulation of SPARC (secreted protein, acidic, rich in cysteine) in the spinal discs of aging mice. SPARC is an extracellular matrix protein enriched in cysteine and its downregulation is linked to degeneration of intervertebral discs and possibly chronic low back pain. Wild-type mice at age greater than seven months developed cold hypersensitivity while SPARC null mice started showing this hypersensitivity at a much younger age of four months. It was the same when the motor function impairment was developed. All six CpGs identified from the mouse SPARC promoter $(-229 /+281$ relative to TSS) were methylated. Following the age, methylation levels of three distal CpGs increased accompanied by a maximal 50\% decrease in SPARC mRNA in the mouse discs. Pharmacological inhibition of DNMT upregulated SPARC mRNA greater than four folds in discs. Reporter gene studies further confirmed that complete methylation of these CpGs suppressed promoter activity. Examination of severely degenerated human discs revealed hypermethylation of 7 out of 12 CpGs found in the human SPARC promoter. Their data suggest that DNA methylation downregulates $S P A R C$ expression that is related to degeneration of discs, which may be related to low back pain. Recently, this group went on and examined the global DNA methylation level in different brain regions in mice subjected to the spared nerve injury and 
experiencing different post-surgical environments [86]. They observed that six months after surgery the global DNA methylation detected by an enzyme-digestion based assay decreased significantly in the prefrontal cortex (PFC) and the amygdala, but not in visual cortex and the thalamus while animals still exhibited mechanical and cold hypersensitivity as well as anxiety. Interestingly, enriched environments helped reduce the abnormal sensory hypersensitivity, and blocked or reversed the reduction of PFC DNA methylation. In comparison, an impoverished condition had no impact. Their findings indicate that to retain the spared nerve injury and maintain the hypersensitivity requires reduction of DNA methylation. It will be very interest to know whether manipulation of PFC DNA methylation is able to alter sensory sensitivity and whether specific gene expression is involved. The authors stated that currently they are searching for the causal relationship of DNA methylation to chronic pain by comprehensive, high throughput analysis of DNA methylation changes and the effect of these changes on individual genes under chronic pain conditions. However, in view of the significant reduction of global DNA methylation from $60 \%$ to $48 \%$ in PFC [86], it is difficult to conclude that it is all related to gene expression. Most methylated CpGs in cells are located in repetitive sequences and intergenic regions, while CpGs relevant to transcription in CGIs, CGI shores, and promoters remain mostly unmethylated and thus will not significantly contribute to the large reduction of the global methylation $[61,76]$. For example, the human genome contains near a half million LINE-1 elements of repeats that can be differentially methylated under different conditions [97101]. More importantly, recent studies indicated that methylation of cytosine residues in $\mathrm{CpH}(\mathrm{H}=\mathrm{A}, \mathrm{T}$, or $\mathrm{C})$ may become dominant in the frontal cortex neurons of humans and mice in adult [102]. Therefore, 5-methylated cytosines (5mCs) may not represent only those in $\mathrm{CpG}$ as thought previously. The means applied to measure methylation is critical to differentiate $5 \mathrm{mCs}$ in different structures. For examples, methylation accessed by antibody specific to 5mCs cannot distinguish $\mathrm{CpG}$ from $\mathrm{CpH}$ while $\mathrm{CpG}$-dependent Beadchip or enzymatic digestion can [82-84].

In an opposite direction of methylation change, Wang et al. reported a small, but significant, increase in global DNA methylation in the spinal cord of rats 14 days after chronic constriction injury (CCI) of the sciatic nerve [87]. They further demonstrated that daily intrathecal injection of the DNMT inhibitor 5-AZA reduced this increase and also attenuated thermal and mechanic hypersensitivity resulting from CCI. However, since behavior was measured soon after daily injection of the inhibitor, the duration of the inhibitory effect of 5AZA is unknown. Interestingly, 5-AZA-treated animals retained methylation levels comparable to the sham group, suggesting that either basic methylation is not impacted by the inhibition of DNMT inhibitor used or the sham group also had a change in the level. They further found that $M e C P 2$ was upregulated at both mRNA and protein levels in the spinal cord. Identification of specific gene(s) undergoing methylation changes and their interaction with upregulated $\mathrm{MeCP} 2$ in the spinal cord will be very helpful to interpret the behavioral change in this model.

Using inflammatory pain models in mice we observed that intrathecal injection of one dose of another DNMT inhibitor (zebularine) prevented or reduced thermal hyperaglesia before or after injection of CFA into the hindpaw [88]. This reduction exhibited a reverse bell 


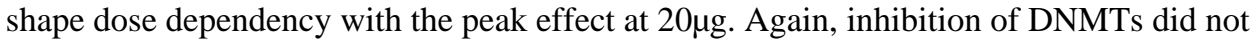
change the base line of the animal behavior. Taken together with Wang's data, we believe that only de novo DNA methylation is involved in the development and/or early phase of maintenance of persistent pain. $\mathrm{Xu}$ and colleagues reported that demethylation of the cystathionine- $\beta$-synthetase $(C B S)$ promoter took place in the DRG and was responsible for inflammatory pain induced by CFA [89]. They found that $C B S$ expression at mRNA and protein levels in ipsilateral DRG was upregulated following CFA injection, and that local inhibition of $C B S$ (intraplantar injection) reversed mechanical hyperalgesia. They analyzed methylation states of two CGIs in the CBS promoter and showed that in DRG of naïve animals the CGI upstream of TSS was methylated at a relatively high level comparable to unmethylated DNA revealed by PCR of bisulfite modified DNA. Success of this measure relies on methylated CpGs within designed primer sequences. They also showed that a 210bp region in the CGI located in intron 1 had less than 10\% of CpGs methylated using cloning and sequencing of PCR products of bisulfite modified DNA. Upon CFA treatment, both CGIs reduced methylation approximately by half. However, the contribution of the minor methylation of the intronic CGI to the transcription should be limited in comparison to the robust change of the upstream CGI. More importantly, only one group of clones of the intronic CGI sequences were shown from control and CFA-treated animals and were not the results of direct sequencing of PCR product as described in the report. In addition, all numbers of clones can only represent one biological sample of DNA extracted from mixed heterogeneous cells and were likely produced by one PCR reaction [82]. Multiple groups of clones from sufficient biological repeats should be taken. In the same study, they further discovered that CFA upregulated mRNAs of Gadd45a and MBD4, but did not alter expression of $D N M T 3 a, 3 b, M B D 2$ and $T D G$ in the DRG. It is interesting to know whether DNA methylation is involved in the expression of these upregulated genes since all of them in the rat genome have CGI either near their TSS or within their genes as revealed by UCSC Genome Browser. In another report, the same group studied the same gene in the DRG of rats that developed diabetes [90]. Following chemically induced diabetes, animals developed gastric hypersensitivity and exhibited $C B S$ upregulation in the DRG. Inhibition of $C B S$ attenuated this hypersensitivity. Again, they observed reduction of DNA methylation in the same promoter regions and believed that it was an underlying mechanism of $C B S$ downregulation. Differential DNA methylation in cortical related genes along with histone modification in a visceral pain model was studied and will be discussed in the next section of chromatin remodeling [103].

Recently, an international collaboration consortium reported their exciting data of human pain studies after performing deep sequencing of antibody precipitated methylated DNA and screened up to 5.2 million loci per person for pain sensitivity related DMR [91]. After comparing data obtained from the blood cell genome of 25 pairs of female monozygotic twins selected for exhibiting distinct heat pain sensitivity on their forearms using one type of pain measure $\left(>2^{\circ} \mathrm{C}\right.$ within the pair) and 50 unrelated individuals, they found a number of so-called pain DMRs between twins within each pair correlated to their discordant pain sensitivity. Within the top 10 of the pain DMRs in the twin cohort this team claimed to have identified a strong association of hypermethylation of the TRPAl promoter with low pain threshold. Less correlation was presented for several other pain-related genes including 
GRIN1, TRPVI and TRPV3 encoding the components of the NMDA subtype of glutamate receptors and transient receptor potential cation channels in the nervous system. From the unrelated individual cohort, they reexamined DMRs gained from twin studies and uncovered a different group of genes including $A N K 3$ and $D C L K 1$. However, it is hard to connect hypermethylation, that suppresses gene expression in most cases, with low pain threshold, i.e., increase in nociceptive sensitivity, since NMDA receptors and TRP channels are considered facilitators of the nociceptive signal $[15,104]$. The downregulation of these genes due to promoter methylation should reduce sensory sensitivity and in turn increase pain threshold. In addition, in this report, all tested individuals or donators showed DNA methylation of these genes in blood cells, skin tissues and two postmortem brains although at different levels. It has been known that expression of TRPA1, TRPV1 and TRPV3 is highly restricted to a subset of nociceptive sensory neurons and spinal neurons, but not in the brain [105-106], although some data suggest that TRPAl and TRPVI are expressed in keratinocytes at a very low level [107]. The critic question then is whether the uncovered methylation represents the mechanism of tissue specific suppression of these genes in nonneural or non-sensory neuronal tissues occurring biologically and thus irrelevant to pain sensitivity. Furthermore, 25 pairs of twins studied had a median age of 62 years indicating strongly the possible impact of age and accumulated environmental exposure on these genes between twins within the pair. Certainly, whether these promoter regions in primary sensory neurons receive the same impact is a very interesting question and requires further investigation.

In a case-control study, methylome of blood cells were also examined from 10 female patients suffering from fibromyalgia characterized by chronic widespread pain [108]. This study utilized a sophisticated platform of HumanMethylation450 Beadchip that covers 485,764 CpGs from CGI, CGI shore and promoters. Methylome from patients were compared with these obtained from 42 comparable health controls. A total of 69 DMRs were identified and $91 \%$ of these were attributable to increased values in fibromyalgia. These DMRs are functionally relevant to genes of BDNF, NAT15, HDAC4, PRKCA, RTN1, and $P R K G 1$, many of which are involved in nociception [15, 22]. However, the same question remains unanswered about how to link DNA methylation of the same gene(s) from circulating cells to neural cells processing nociceptive signal in view of the tissue specificity of DNA methylation.

In addition to the reports above, another group examined DNA methylation of the opioid receptor genes in drug addicts [109]. A SNP in the OPRM1 gene (118A/G, rs 1799971) creates a new $\mathrm{CpG}$. This newly formed $\mathrm{CpG}$ indeed displayed hypermethylation in postmortem brain of chronic opiate addicts and very likely was responsible for low expression of $O P R M l$ and reduced ligand binding in the thalamus. The same group reported that $O P R M I$ displayed hypermethylation in the blood cells of methadone-substituted former opiate addicts as well as of chronic opioid addicts suffering from chronic pain [101]. One region in the $O P R M 1$ promoter CGI was analyzed by pyrosequencing of bisulfite-modified DNA. Not surprisingly, only 1 out of $22 \mathrm{CpGs}$ within this region showed significant increase in opioid-treated addicts. To study mechanism underlying persistent oral cancer pain, Viet and co-workers found massive hypermethylation of the EDNRB gene, encoding 
endothelin $\mathrm{B}\left(\mathrm{ET}_{\mathrm{B}}\right)$ receptor, from biopsy of oral squamous cell carcinoma tissues that are painful lesion and do not express $\mathrm{ET}_{\mathrm{B}}$ instead of endothelin $\mathrm{A}\left(\mathrm{ET}_{\mathrm{A}}\right)$ receptor encoded by the EDNRA gene [110]. This hypermethylation was accompanied with EDNRB mRNA at a level approximately $1 / 10$ of normal control. In comparison, oral dysplasia, that is not painful, exhibited significantly less methylation of the EDNRB promoter than cancer cells although mRNA expression was not examined from dysplasia patients. In line with some previous findings of promoter methylation, the $E D N R B$ promoter exhibits differential methylation on individual $\mathrm{CpGs}$ in all examined tissues. It has been known that $\mathrm{ET}_{\mathrm{B}}$ is analgesic [111], while $\mathrm{ET}_{\mathrm{A}}$ facilitates nociceptive signals [112]. Both $\mathrm{ET}_{\mathrm{A}}$ and $\mathrm{ET}_{\mathrm{B}}$ are receptors for endothelin-1 that is secreted from cancer cells. Data collected from the above studies support the hypothesis that cancer cells directly contribute to the relevant pain [113], and also strengthen the notion that methylation of a few critical CpGs may be sufficient to regulate transcription.

Studies from animal models and humans discussed above demonstrate that DNA methylation is critical for the development and/or maintenance of hypersensitivity to pain and this mechanism involves both MBD and reversible DNA methylation. Future work should focus on identify genes regulated by DNA methylation in a tissue/cell type specific manner along with dynamic information directly relevant to pain. This direction will ultimately help us to better understand the underlying mechanisms and lead to the development of effective therapeutics. Some general issues should also be considered. First consideration should be given to focus on specific genes or global evaluation of DNA methylation, to which it is really crucial to have specific loci or CpGs revealed. Importantly, it has been already known that methylation of a few critical CpGs in the promoter region is sufficient to suppress the transcription as exemplified by studies of the OPRM1 mutant described above [109]. Functional evaluation of methylated CpGs is important to annotate the event. As a consequence, transcription products should be determined and be gene specific due to the CpG locus. Second, DNMT activity to specific genes should be targeted pharmacologically. Third, blood cells are commonly studied in neurological disorders involving abnormalities of the CNS, which may be misleading. It is particularly true for studies of DNA methylation in view of its tissue specificity and the large heterogeneous cell types in the CNS as differential DMRs across distinct brain regions were already reported [114].

The methyl group on the pyrimidine ring of cytosine residues can be oxidized to produce 5hydroxymethylcytosine $(5 \mathrm{hmC}), 5$-formylcytosine $(5 \mathrm{fmC})$ and 5-carboxycytosine $(5 \mathrm{caC})$ [115-117]. The presence of $5 \mathrm{hmC}$ in the genome was found from brains of rat, mouse or frog in 1972 [115] and drew much attention after the enzymes responsible for its production were identified in 2009 [118] and their enrichment in embryonic stem cells and neural cells was noticed [119-121]. Because of the chemical nature, most assays of DNA methylation cannot distinguish these oxidized products from $5 \mathrm{mC}$. Only a few chemical analyses, antibodies and combination of modified and native bisulfite DNA sequencing are able to analyze these products $[115,118-119,122-126]$. These oxidized mCs are predicted as intermediates of cytosine demethylation and found to interfere with function of some MBDs or display differential affinity to other MBDs and transcription factors, indicating a potential 
role in epigenetic regulation [117, 127-130]. Currently, the role of these modified 5mCs in epigenetic regulation of persistent pain remains totally unexplored.

\section{Chromatin remodeling and the histone code}

In the nucleus, most genomic DNAs are tightly compacted around the histone core consisting of $\mathrm{H} 2 \mathrm{~A}, \mathrm{H} 2 \mathrm{~B}, \mathrm{H} 3$ and $\mathrm{H} 4$ histones to form nucleosomes that are connected by the linker H1 histone plus linker DNA [131-132]. This structure maintains stability of the genome and prevents other nuclear proteins from accessing genomic DNA. In a living cell the nucleosome is dynamically remodeled by nuclear proteins coworking with posttranslational modifications (PTMs) of specific residues within the N-terminal tails of histones in the core. Thirteen classes of PTMs have been described, including acetylation, methylation, phosphorylation, and ubiquitination [28, 133-134]. These modifications alter the structure and function of the histone core and thus are thought as the histone code that is added by relevant enzymes as the code "writer", removed by other enzymes of "eraser" and recognized by a number of nuclear proteins of "reader" [28, 36, 131-132, 135].

About 20 of all lysine $(\mathrm{K})$ residues in the histone core, mostly in their N-tails, in euchromatin and facultative heterochromatin can be acetylated by histone acetyltransferase (HAT) resulting in release of tightly coiled DNA [28, 136-138]. Conversely, acetylated histones can be deacetylated by histone deacetylase (HDAC) thus re-establishing the nucleosomal structure. Therefore, histone acetylation is traditionally thought to activate gene expression while deacetylation is to suppress gene expression $[28,32,131,138]$. In cells a dynamic balance between HAT and HDAC activity maintains the level of histone acetylation to archive a given pattern of gene expression. HAT activity is often associated with many transcription factors while HDAC has at least four classes encoded by more than 20 genes (Class I, IIa, IIb, IV and III (or Sirt)) and displaying differential and dynamic subcellular localization [138-139]. Other histone modifications may modify histone core structures, and produce differential effects on gene expression. Both lysine (about 6 in the core) and arginine (over 30) with three sensitive sites on each residue can be methylated [28, $137,140]$. Methylation results in reshaping histone structures so as to interact with nuclear proteins for chromatin remodeling of differential gene expression. For example, trimethylated $\mathrm{H} 3 \mathrm{~K} 4$ and $\mathrm{H} 3 \mathrm{~K} 27$ are hallmarks of gene activation and repression, respectively [141]. About dozen serines and threonines, a few tyrosines and even two histines are subjected to phosphorylation and involved in chromatin remodeling [137, 142143]. Recognizing the robust and unidirectional effects on chromatin remodeling and gene expression and aided by the availability of many specific inhibitors, the impacts of histone acetylation on various biological events and pathological conditions have been intensely studied. Inspired by the advance of our understanding of other histone modifications, more studies of the effects of methylation and phosphorylation on persistent pain have emerged recently. In general, two groups of opposite results have been reported regarding attenuation of hypersensitivity by increase in histone acetylation resulting from HDAC inhibition or by its reduction produced by HAT inhibition. In table 2, we highlight studies of different persistent pain models with chromatin remodeling and will discuss these below. 
Inflammatory pain-HDAC inhibitors (HDACi) are able to attenuate various types of persistent pain associated inflammation [144-145]. All studies of inflammatory pain indicated that HDACi or increase in histone acetylation in the pain circuitry is analgesic.

Zhang et al. investigated histone modifications and expression of GAD2 encoding GAD65 protein in the nucleus raphe magnus (NRM) of the brain stem from rats inflamed with CFA and suffering from spinal nerve ligation (SNL) [146]. Their data indicated that, while producing hypersensitivity, inflammation or SNL induced a decrease in GABAergic synaptic function due to a reduction of presynaptic GABA release, downregulation of GAD65 mRNA and proteins and global hyperacetylation of $\mathrm{H} 3$ and $\mathrm{H} 4$ in the NRM. However, inflammation reduced binding of acetylated $\mathrm{H} 3(\mathrm{acH} 3)$ to the $G A D 2$ promoter in two of four regions examined. This reduction occurred only in the late stage, i.e., 3 days after CFA and 21 days after SNL. Importantly, continuous infusion of HDAC inhibitors, TSA or SAHA, into the NRM reversed the CFA-induced changes in wild type mice, but not the hypersensitivity developed in $G A D 2-/-$ mice that already had a relatively mild basal hypersensitivity and were able to develop full response to CFA only at 1d, but recovered at $3 \mathrm{~d}$. These results demonstrated the participation of epigenetic mechanisms in control of central sensitization for persistent pain although the impact of HDACi on neuropathic pain in the SNL model was not examined. In addition, the detailed molecular mechanism of acH3 interaction with the GAD2 promoter, e.g., whether the putative CRE sites in the examined promoter regions are functional, needs further investigation. Their data exemplified a case in which the global change of histone acetylation may differ or be separated from that associated with a specific gene. Clearly, only the changes on a given gene can functionally regulate transcription.

Using a CFA inflammatory pain model in mouse, we observed that inflammatory thermal hyperalgesia can be prevented or reduced by one dose of intrathecal injection of inhibitors specific to class IIa HDAC [147]. We further found that expression of class II HDACs in the spinal dorsal horn were increased following the peripheral tissue damage induced by CFA. Given the fact that histone acetylation was enhanced in the spinal cord after inhibition of HDACs, we concluded that histone acetylation-related epigenetic regulation participates in the development/maintenance of inflammatory thermal hyperalgesia. However, we did not observe significant global change (expected reduction due to HDAC expression) of histone acetylation in the spinal cord after CFA injection to the hind paw. This may be due to the following possibilities. First, the histone core is formed by an octamer of a pair of H2A, H2B, H3 and H4 [131-132]. Each single histone contains multiple lysine residues sensitive to acetylation [134]. Like most reported studies, we only examined a few of the lysine residues (H3K9 and $\mathrm{H} 3 \mathrm{~K} 18$ here), and thus had no full view of all lysine residues under the studied condition. This point should be considered when interpreting published data in the literature. Second, it has been expected that HDACs have gene specificity although it still remains largely unknown [148-149]. It is reasonable to predict that a particular set of genes are targeted by increased HDAC(s) for a given event [138]. Third, technically, we suppressed a large number of HDAC molecules using the inhibitors and did not have information of the location of HDACs at the subcellular level [139]. Last, we recognize that a large number of non-histone proteins are subject to acetylation and thus are the potential 
substrates of HDACs even though the specificity of subclass HDACs to individual proteins is unclear. Importantly, many of these proteins are involved in nociceptive signaling revealed by gene targeting studies. Our data mining of 407 genes in the Pain Genes database (Up to Feb, 2014) with 7,755 unique acetylated human and rodent proteins from three databases ASEB, UniProtKB (www.uniprot.org), and Lundby et al. resulted in 73 proteins that were found acetylated either in cultured cells or in tissues of naïve animals [22, 150152]. Acetylation may modify functions of some of these proteins. For example, estrogen receptor alpha can be acetylated at several $\mathrm{K}$ residues with different effects. Acetylation at K302/K303 represses transcriptional activity while acetylation at K266 and K268 enhances DNA binding and transactivation activity [153-154]. Therefore, as discussed above, the global change of histone modification is not informative for regulation of specific gene(s). It is important to reveal the interaction of histones with individual promoters using techniques, such as chromatin immunoprecipitation (ChIP), and thus understand the impact of histone modifications on gene expression.

Neuropathic pain-Various neuropathic pain models have been used to study the impact of gene expression regulated by epigenetic mechanisms involving histone modification.

Kiguichi and co-works explored the epigenetic regulation of chemokine cascades in chronic neuroinflammation following nerve injury [155-156]. First, they showed that the injured sciatic nerve (SCN) in mice after partial sciatic nerve ligation (PSL) exhibited transient 40and 100-fold upregulation of mRNAs of cytokine CXCL2 (or MIP-2) and its receptor CXCR2, respectively, with a peak at 1 day. Upregulated mRNAs quickly declined to a couple of fold higher than sham 3 days after PSL [155]. They found that neutrophils and macrophages were the most responsive cells in the injured nerve. Perineural injection of antibody to neutralize CXCL2 or of SB225002 to inhibit CXCR2 attenuated thermal hypersensitivity, but had a minor inhibitory effect on mechanical allodynia (tactile). They also found increased binding of $\mathrm{H} 3 \mathrm{~K} 9 \mathrm{ac}$ to the $C X C L 2$ and $C X C R 2$ promoters during the same time course of mRNA upregulation. They revealed that global signals of H3K9ac increased specifically in neutrophils labeled by LyG6 and macrophages stained by T4/80. Systematic inhibition of HAT with one i.p. its inhibitor anacardic acid (ACA) before the surgery significantly reduced upregulated $C X C L 2$ and $C X C R 2$ mRNAs 1 day after PSL and attenuated hypersensitivity 7 days after PSL. This pretreatment also produced minor, but significant, reduction of $\mathrm{H} 3 \mathrm{~K} 9 \mathrm{ac}$ binding to the CXCL2 and CXCR2 promoters. Recently, they presented evidence showing epigenetic regulation of another set of cytokines for a relatively long period [156]. They transplanted bone marrow cells isolated from EGFP-Tg mice to the circulation of wild-type mice and confirmed that macrophages from transplants infiltrated into injured SCN 1day after surgery. They found that injured SCN expressed robustly increased mRNAs of $C C L 2$ (> 10 fold vs. sham), CCL3 (>100 fold) and their receptors (CCR2 and CCR1/CCR5, respectively). Increase in CCL2 mRNA peaked $12 \mathrm{hr}$ after surgery and declined to the sham level by 7 days while $C C L 3$ peaked at 1 day and remained significantly high through the studied time, 14 days, although it declined to only $1 / 5$ of the peak. In contrast, their receptors' mRNAs increased and stayed high through the time period studied. Pretreatment of animal by i.p. ACA significantly attenuated the upregulation of all mRNAs at 1 days post PSL. They found that injured SCN had increased 
binding of $\mathrm{H} 3 \mathrm{~K} 9 \mathrm{ac}$ and $\mathrm{H} 3 \mathrm{~K} 4 \mathrm{me} 3$, but not $\mathrm{H} 3 \mathrm{~K} 9 \mathrm{me} 3$, to the CCL2 and CCL3 promoters after PSL. These changes mostly took place in infiltrated macrophages co-localized with their proteins 1 day post PSL. Interestingly, inhibition of HAT also reduced expression of $C C R 1,2$ and 5. Given their expression in DRG neurons, it is very likely that histone modifications participate in the transcription of these genes in DRG. Apparently, immunohistochemical results represent the global change of modified histones that can be separated from the local changes on individual promoters as Zhang's report indicated [146].

Another group investigated HAT activity associated with transcription coactivator p300 in CCI-induced neuropathic pain in rats [157]. They observed that $p 300$ expression in the spinal cord was upregulated 14 days after CCI and intrathecally injected p300 shRNAexpressing lentivirus reduced this upregulation as well as attenuated upregulated $C O X 2$ mRNA in the spinal cord. More importantly, these reductions were accompanied with attenuation of thermal and mechanic hypersensitivity induced by CCI. Intrathecal administration of HAT inhibitor C646 reproduced the results. They also provided evidence showing that p300 protein co-localized with the COX2 protein in spinal dorsal horn neurons in naive rat. Recently, they further investigated p300/CBP that represents two functionally interchangeable proteins [158] with expression of BDNF in the spinal cord [159]. Treating animals systemically (i.p.) with another HAT inhibitor curcumin 7 days after CCI for consecutive 7 days, they were able to reduce hypersensitivity of neuropathic pain. Both p300 and CBP were colocalized with BDNF or COX2 in the spinal dorsal neurons. It has been known that CCI animals have BDNF and $C O X 2$ upregulation in the spinal cord. In line with these facts, nerve injury resulted in increase in binding of p300, CBP, and H3K9ac, but not $\mathrm{H} 4 \mathrm{~K} 5 \mathrm{ac}$ to the $B D N F$ promoter, and all of these proteins to the COX2 promoter. Curcumin treatment for 7 days blocked these increases that were consistent with changes of relevant mRNAs, but not proteins.

In consistent with the inhibitory effect of HAT inhibitor (HATi) on hypersensitivity in PSL and CCI models above, a study of incisional pain also indicated that mechanical hypersensitivity and its priming in mice after hindpaw skin incision was attenuated by ACA, following daily i.p. for 2 days before and 4 days after the incision [160]. In contrast, administration of SAHA in the same protocol exacerbated mechanical hypersensitivity, but not its priming, although only one high dose $(50 \mathrm{mg} / \mathrm{kg})$ was tested. Interestingly, both inhibitors had no impact on thermal hypersensitivity. Incision upregulated acetylated H3K9, cytokine CCL1 and its receptor CXCR-2 in the spinal neurons. However, systemic SAHA treatment induced or further enhanced expression of all of them, while neither incision nor SAHA changed expression of CCL2 that is another ligand of CXCR2. Whether SAHA is able to induce the same upregulation on naive animals was not tested. Binding of acetylated $\mathrm{H} 3 \mathrm{~K} 9$ to the $C C L 1$ and $C X C R 2$ promoters was largely enhanced in SAHA-treated animals although the impact of the incision on the binding was not evaluated. Interestingly, the effect of ACA on upregulated CXCR2 expression was not examined disregarding that ACA was able to attenuate mechanical hypersensitivity and pharmacological inhibition of CXCR2.

Uchida and co-workers have studied epigenetic regulation of chromatin remodeling in mouse PSL model. Initially, they found that PSL mice in their DRG upregulated mRNA of transcription factor REST (or NRSF) from its promoter II being associated with an increase 
in acetylated $\mathrm{H} 4$ (acH4), but not acH3, to this promoter at least 7 days after nerve injury [161-162]. Interestingly, results of immunohistochemistry indicated that most upregulated $R E S T$ were in DRG neurons rather than in non-neuronal cells as found by others previously [163]. They identified that upregulated REST interacted with its cis-element RE-1 (or NRSE) in the promoters of OPRM1, Nav1.8 and Kv4.3 [161-162]. They showed that the binding was responsible for the downregulation of their mRNAs in the injured DRGs since downregulation of REST by antisense oligonucleotide restored expression of these mRNAs. Interestingly, downregulated mRNAs of TRPAI and TRPM 8 were also restored though no evidence of REST interaction to their promoters was shown. REST was proposed to participate in chromatin remodeling and thus in epigenetic regulation of target genes [163]. All of these changes were found positively correlated to the changes in hypersensitivity of C-fibers, instead of A $\beta$ - and A $\delta$-fibers. Recently they found that downregulated Nav1.8 mRNA in the injured DRGs was reversed by intraplantar injection of HDACi, VPA or TSA, following one pre-surgery dose and daily dose after surgery for 3 days [164]. This finding suggests that class I and IIa HDAC are involved. At the same time, the channel function in $\mathrm{C}$-fibers instead of $\mathrm{A} \beta$ - and $\mathrm{A} \delta$-fibers were recovered partially and maintained as long as daily HDACi was provided. Importantly, injury-induced thermal and mechanical hypersensitivity was attenuated by this local administration of HDACi supporting the analgesic effect of histone acetylation. Application of another strong HDACi, SAHA, resulted in similar effects, and also restored downregulated TRPVland TRPM8. Very interestingly, they demonstrated that HDACi restored acH3 and acH4 binding to the RE-1containing regions in the Nav1.8 promoter supporting the interaction between acetylated histones and REST. Taken together with their earlier findings, their data indicate that HDACi administered peripherally was able to reach nociceptors in DRG and further modify histones thus providing a simple approach of drug delivery to treat neuropathic pain. However, how HDACi restores expression of TRPVI and TRPM8, and whether these channels are critical for $\mathrm{C}$-fiber functions are interesting questions. In contrast to reduced binding to the Nav1.8 promoter, but similar to increased binding to the REST promoter, acH3 and acH4 were found by this lab to increase binding to the 1st $B D N F$ promoter and thus upregulating this gene after nerve injury [165]. Their data enforced the concept that interaction of modified histones to gene specific promoters is a dynamic process and can be separated from the global change of histone acetylation even though the later may affect individual genes.

It is known that neuropathic and inflammatory pains are different. Interestingly, two laboratories showed that class I HDAC, mainly $H D A C l$, is important for neuropathic pain while Class II in important for inflammatory pain [147, 166-167].

Cherng et al. found that an ipsilateral increase in the spinal HDAC1 protein and reduction of $\mathrm{acH} 3$ occurred in a reverse time course after spinal nerve ligation (SNL) in rats [166]. Interestingly, these changes took place through the same time span during which animals were developing thermal hypersensitivity. In contrast, tactile allodynia developed quickly 1 day after SNL. Intrathecal injection of Baicalin, a flavonoid-anti-inflammatory compound purified from plant, totally reversed thermal hypersensitivity, but only partially mechanical allodynia. Interestingly, they found that altered $H D A C l$ and acH3 signals were reversed 
completely to the basal level, apparently at 2 3 hrs after Baicalin. Co-injected morphine had an additional analgesic effect, but not on $\mathrm{HDACl}$ and acH3 expression. Based on these results, it seems that the altered $\mathrm{HDACl}$ and acH3 expression occurred quickly, although it is uncertain whether this is causal to the reduction of sensory hypersensitivity. The quick regulation may involve mechanisms, such as microRNA regulation of protein translational rate.

In comparison, Denk et al. also studied the impact of class I HDAC inhibitors (MS-275 and MGCD0103) on thermal and mechanical hypersensitivity after SNL, PSL and peripheral neuropathic pain induced by d4T (antiretroviral drug) in rats [167]. They continuously provided HDACi to the intrathecal space of animals using an osmotic pump. Their studies indicated that hypersensitivity after nerve injury or drug injection was reversed with pretreatment for at least 5 days before the surgery, while post-treatment was ineffective. The recovery started at day 5 6 for both thermal and mechanical hypersensitivity for the 2 tested doses and continued until the pump dried out 9 12 days after surgery. Their Western analyses revealed that $\mathrm{H} 3 \mathrm{~K} 9 \mathrm{ac}$ signal in the spinal dorsal horn was higher in HDACi-treated animals than vehicle-treated animals on day 14 after surgery or d4T treatment, and the increase persisted at least 2 days after the pump dried out. In contrast, following this long term and ample HDACi treatment, DRGs did not show any change of H3K9ac. ChIP data showed that this long and ample HDACi treatment resulted in significant binding of $\mathrm{H} 3 \mathrm{~K} 9 \mathrm{ac}$ to the promoters of HDAC1, MeCP2, Cacna2d1, instead of HDAC2 and HDACl1.

Consistent with $\mathrm{H} 3 \mathrm{~K} 9 \mathrm{ac}$ immunoblot data, these changes were seen only in the spinal dorsal horn. However, the following mRNA microarray analysis did not reveal expected changes of gene expression. Their data demonstrated again that neuropathic pain is a severe event and its epigenetic correction needs a large dose and long-term treatment of HDACi. Using the primer sequences of the $H D A C l$ ChIP provided, we searched the genome database at Genbank and found this primer pair covers an 82-bp region within the first intron. Future studies should employ inhibitor(s) to other classes of HDACs and further establish the involvement of HDAC1 in neuropathic pain.

Valproic acid (VPA) as an anticonvulsant inhibits other molecular mechanisms in the nervous system in addition to HDAC [168]. Several laboratories have also investigated its impact on persistent pain. Hobo and colleagues fed VPA to rats 3 weeks after SNL and obtained a quick and increasing analgesic effect $2 \mathrm{hrs}$ after one oral dose from 100 to 600 $\mathrm{mg} / \mathrm{kg}$ [169]. Although this effect did not last long, after 3 consecutive daily treatments twice per day, pain attenuation can be significantly stable overnight at least until next morning before the first daily dose. Ample dose and duration are needed without detectable side effects from animal studies and stable analgesic effects suggest potential application of this drug in the treatment of neuropathic pain. These authors also found that expression of glutamate transporter-1 (GLT-1) and glutamate-aspartate transporter (GLAST) in the spinal dorsal horn were downregulated, which were restored by feeding VPA. Interestingly, both pain hypersensitivity and glutamate transporter expression were partially reversed by VPA. Further pharmacological studies confirmed that VPA's analgesic effect was largely blocked by intrathecal injection of GLT-1 antagonist dihydrokainic acid to rats fed with VPA daily for 10 days, but significantly, enhanced by intrathecal glutamate transporter activator 
riluzole after 15 daily feeding with VPA. Genetic manipulation with five daily intrathecal siRNA injection to knock down GLT-1 also reduced VPA's effect [170]. In comparison, using HDACi to class I, Denk et al. could not attenuate existing or post-surgery hypersensitivity induced by SNL in rats [50]. Because VPA targets broad HDACs, it is quite possible that VPA acts on another class of HDAC or utilizes other pathways such as GABAergic activity in the brain stem to interfere with pain signals in the late stage or in the development of persistent pain [146, 168].

Kukkar et al. fed rats with sodium butyrate, a weak HDACi at doses of 100 to $400 \mathrm{mg} / \mathrm{kg}$ for 14 days starting right before CCI surgery and found that neuropathic pain hypersensitivity induced by CCI, including cold and mechanical allodynia, thermal hyperalgesia, were dosedependently attenuated. They also revealed that at the end of 14 days of feeding, increased TNFa content in the injured SCN was significantly reduced by this HDACi [171]. Considering the target specificity of sodium butyrate [172], class I and II HDACs may be involved in CCI-induced neuropathic pain.

The role of class III HDAC, i.e., $\mathrm{NAD}^{+}$-dependent histone deacetylase Sirtuins in the neuropathic pain has been also studied in the CCI model. Yin et al. found that CCI downregulated the spinal Sirt1 and upregulated global acH3 level [173]. Intrathecal administration of resveratrol (Sirt1 activator) partially attenuated thermal and mechanical hypersensitivity and $\mathrm{H} 3$ acetylation, and interestingly restored partial Sir1 expression. Maintenance of these changes needed consecutive activation of Sirt1. Clearly thermal hypersensitivity was more sensitive to Sirt1 activation. Interestingly, another lab found that intrathecal application of resveratrol attenuated morphine tolerance (MT) developed in rats after twice daily i.p. for six days [174]. They further found that Sirt 1 expression at mRNA and protein levels in the spinal cord of MT rats was significantly downregulated. Resveratrol treatment for 7 days largely restored Sirt 1 expression in the spinal dorsal neurons. Both studies have observed that resveratrol was able to upregulate Sirt 1 expression even though the underlying mechanism deserves further investigation.

Toxins may damage nerve fibers or neurons and produce neuropathic pain. Tsai et al. evaluated the correlation between spinal histone 3 methylation and the analgesic effect of morphine plus opioid receptor antagonist naloxone on thermal hyperalgesia induced by pertussis toxin (PTX) [175]. First, they were able to generate persistent thermal hyperalgesia in rats by intrathecal delivery of PTX. Then they observed that this hyperalgesia could be attenuated only by intrathecal injection of $15 \mathrm{ng}$ of naloxone, but not by $10 \mu \mathrm{g}$ morphine. However, consecutive injection of naloxone followed by morphine resulted in a robust analgesic effect comparable to morphine's effect on animals without PTX insult. From a Western analysis, they found that PTX increased spinal levels of H3K4m1, H3K4m 2 and $\mathrm{H} 3 \mathrm{~K} 9 \mathrm{~m} 3$ and these increases were reduced only by combined treatment indicating a correlation between reduction of methylation in these histone sites and analgesia.

Imai and co-workers searched the nociceptive signaling flowing from the peripheral to central nervous system [176]. They nicely illustrated that the signal of nociceptive hypersensitivity was carried on by IL-6 from primary afferents to the spinal cord after PSL. By screening responsive genes in the spinal cord via mRNA profiling, they uncovered 20 
upregulated mRNAs and on the top was chemokine (C-C motif) ligand 7 (CCL-7, also MCP-3 for protein). They further located $C C L-7$ expression to activated astrocytes in the spinal cord and found that astrocytes released excessive MCP-3 to act on its receptor CCR-2 on activated microglia. Hypersensitivity was attenuated by interrupting this pathway by intrathecal antibody blocking of released MCP-3 or by antagonist to CCR-2. They further demonstrated that the expression of $C C L-7$ in astrocytes relied on epigenetic activation of transcription via reducing inhibitory $\mathrm{H} 3 \mathrm{~K} 27 \mathrm{~m} 3$ binding to the $C C L-7$ promoter rather than increasing binding of acetylated $\mathrm{H} 3$, active $\mathrm{H} 3 \mathrm{~K} 4 \mathrm{~m} 3$ or $\mathrm{H} 3 \mathrm{~K} 9 \mathrm{~m} 3$ to the promoter [176]. Their findings also implicate the possible mechanism underlying the transition of acute pain to chronic pain by epigenetic regulation in spinal astrocytes since this histone-involved $C C L-7$ expression took place 4 weeks after the surgery.

Visceral Pain-The involvement of histone acetylation in visceral pain has been studied in two animal models, endometriosis and colon distention. Gou and colleagues evaluated the therapeutic effect of HDACi on endometriosis in female adult rats induced by autotransplanting pieces of uterus (ENDO) or fat (sham) to the pelvic cavity [177-178]. They administered VPA orally, daily starting before surgery and continuing for 4 weeks and found that the lesion size and thermal hyperalgesia in ENDO rats were significantly attenuated. They further tested another HDACi TSA via daily subcutaneous injection for 4 weeks and repeated the observation [177]. Their results suggest that VPA more likely acts on a different mechanism in endometriosis because of following two reasons. First, VPA required long-term treatment to be effective. Second, TSA, a more specific and potent HDACi, produced insufficient analgesia.

Recently, Winston et al. explored epigenetic mechanisms underlying pronociceptive gene expression during chronic stress in early life and its impact on irritable bowel syndrome (IBS)-like visceral hypersensitivity occurring in the adult [179]. They generated prenatal chronic stress by applying heterotypic intermittent chronic stress (HeICS) to pregnant rats and found that female offspring developed a stronger and longer lasting visceral hypersensitivity after a 2 nd exposure to the same stress as an adult. Upregulated protein levels of BDNF, a pro-nociceptive trophic factor, in the lumbosacral dorsal horn was found to be well correlated with the exacerbation of hypersensitivity in female, but not in male offspring. Blocking the BDNF receptor, TrkB, and knocking down BDNF expression by siRNA via intrathecal injection attenuated this increased visceral hypersensitivity in female offspring. They found that this sexually dimorphic expression of $B D N F$ was supported by an mRNA variant transcribed from the alternative first exon that is governed by the 9th core promoter and this variant is associated with increased binding of RNA Pol II and acH3, and decreased HDAC1 binding. They treated adult female animals daily with the HAT inhibitor curcumin or ACA during the 9-day stress period and confirmed that this neonatal stress associated hypersensitivity, and BDNF upregulation at both protein and mRNA levels were attenuated.

The controversy of distinct histone acetylation effects also was seen from studies of visceral pain. Tran et al. examined the impact of stress on IBS-like visceral pain via epigenetic regulation using their model of repeated water avoidance-stress induced visceral hypersensitivity in rats [103]. They treated animals with HDACi TSA daily via the 
intracerebroventricular cannula for the whole 7-day course. This treatment significantly attenuated stress-induced visceral hypersensitivity that was quantified by the visceromotor response measure. In separate animals, they examined the expression and the methylation status of the glucocorticoid receptor $(G R)$ and corticotropin releasing-factor $(C R F)$ genes in the amygdala. Their findings indicated that stress increased $G R$ promoter methylation and thus downregulated its mRNA, while $C R F$ underwent totally opposite changes, indicating that DNA methylation is involved. However, whether the change of DNA methylation and relevant gene expression contributes to the visceral pain and how HDACi impacts DNA methylation of these two genes are remaining questions to be answered. Again, their results of CRF methylation exemplify the concept that methylation change in a few $\mathrm{CpG}$ is sufficient to impact transcription. Their data showed that only one of nine $\mathrm{CpGs}$ in the examined $C R F$ promoter region displayed reduced methylation after the stress and this reduction was concomitant with its mRNA increase.

The potential epigenetic regulation of IBS has been recently examined and proposed by Vaiopoulou et al. [180].

Other persistent pain conditions-Long-term morphine treatment may result in not only tolerance, but also hypersensitivity. Different from studies reported by $\mathrm{He}$ and coworkers who applied steady amounts of morphine for 7 days to produce MT and found that Sirt1 was involved [174], Liang et al. treated mice with increasing amount of morphine for 4 days and were able to detect mechanical and thermal hypersensitivity in addition to MT [181]. They treated these animals with HAT inhibitor (curcumin) and HDACi (SAHA) in the presence of morphine treatment. Curcumin largely attenuated all sensory hypersensitivity and MT after 4 days treatment. In contrast, SAHA enhanced morphine's effect, and was able to sustain a significant portion of these changes for an additional 4 weeks after termination of morphine. Examination of histone acetylation revealed that H3K9ac instead of H4K16ac in the spinal dorsal horn was enhanced by morphine and that spinal HDAC activity was reduced while HAT activity remained similar to control. For target gene studies, they showed that $B D N F$ mRNA and promoter binding to H3K9ac increased following morphine treatment. Compared to the reduction effect of Sirt1 inhibition, it seems that either different classes of HDAC have opposite effects or at the different stage of morphine tolerance/hypersensitivity HDAC plays an opposite role in nociceptive behavior. Neither study compared all classes of HDAC inhibition on both early and late stages of morphine tolerance/hypersensitivity. Both groups did not examine the status of opioid receptors whose genes indeed are sensitive to DNA methylation [96].

Liu et al. studied cancer pain by inoculating mammary gland carcinoma cells subcutaneously or into the tibia bone of rats and were able to induce thermal and mechanical hypersensitivity on limb 3 days after the inoculation [182]. They inhibited lysine-specific demethylase 1 (LSD1) systematically by daily i.p. administration of its inhibitor pargyline from day 3 to day 14 after the inoculation and attenuated thermal and mechanical hypersensitivity. They concluded that LSD1 is highly expressed in cancer cells resulting in increases in hypersensitivity. However, since LSD1 also targets histones and systematic inhibition of this enzyme may impact histone modification in all cells involved in the pain circuitry, the contribution of histone methylation to this analgesic effect cannot be excluded. 
A number of issues should be considered for most studies of histone acetylation in chromatin remodeling of epigenetic regulation in view of chronic pain studies discussed above and for a general view. First, there are four major histones, i.e., H2A, H2B, H3 and $\mathrm{H} 4$, involved in chromatin remodeling. Each has several lysines in and away from the $\mathrm{N}$ terminals, being subjected to acetylation. However, very often, only a few of these lysines were examined or only a few were found to show changes by a given study. The status of other lysines under the condition studied remains unknown. It would be helpful to have full pictures of acetylation statues for a correct understanding of the condition studied. This is true for studies of other PTMs of histones. Second, in some cases, the interaction of acetylated histone(s) with the genomic DNA, very often, the promoters, was investigated. Usually, the short sequences (often $<1 \mathrm{~kb}$ ) surrounding TSS were examined by ChIP. The significance or function of the region(s) showing modified interactions with histones was very often unavailable. Even in cases where the region contains cis-element(s) for transcription factor(s) of interest, the functionality of these elements was not tested and these elements can only be considered putatively involved. It should be noted that a given ciselement may interact with one active transcription factor and upregulate transcription, or may interact with another inhibitory transcription factor and suppress transcription under different conditions [183-184]. Besides, the sequences flanking the consensus may influence the binding [183]. On the other hand, a given transcription factor may activate one gene, but suppress another gene, likely dependent on local availability of other nuclear factors [185-189]. Third, it is assumed that acetylated histones will become dissociated from the genomic DNA. Thus, it is reasonable to expect that acetylation will decrease histone binding to the promoter. However, the current view is that increased binding of acetylated histones to the promoter represents a positive correlation although again no functional impact of this change on promoter activity has been examined. Supporting this notion, it has been found that hyperacetylated histones are associated with active promoters while hypoacetylated histones with inactive promoters [190]. However, experimentally it has been observed that inhibition of HDAC resulted in upregulation of one set of genes, but also produced downregulation of another set of genes in the CNS as revealed by mRNA profiling [191-193]. Last, there is a concern about how the drug delivery route connects epigenetic mechanisms to the alteration of nociceptive hypersensitivity. It has been known that almost every cell in multi-cell organisms has epigenetic mechanisms and that nociceptive signals are generated and processed by multiple organs/systems directly and indirectly. Therefore, it will be unclear how and where the systematically administered drugs act on cellular epigenetic mechanisms and modify nociception.

\section{Non-coding RNA (ncRNA)}

Since 90's, many small RNAs that do not encode protein or participate in protein translation such as transfer RNA and ribosomal RNA have been found functional in regulating protein translation, mRNA stability and even transcription rate [33, 194-195]. In year 2007, an international collaboration consortium, ENCODE, concluded in a dozen publications after initially sophisticated analyses of $1 \%$ of the human genome that most human genome (up to 93\%) are pervasively transcribed instead of being non-transcribed "junk DNA" [196-197]. Although the nature of most of these transcripts has not been studied, it is clear that they do not encode proteins and thus belong to ncRNA. Until today many types of long- or short- 
ncRNAs have been identified [198]. The first group of such small RNAs is microRNA (miRNA) [199-200]. One important function of ncRNAs is to regulate gene expression at different levels from transcription to translation [33, 199, 201]. In addition, often ncRNA expression is impacted by environmental cues, thus matching the concept of epigenetic regulation of 'independent of genomic DNA sequences', and 'in response to environmental changes' such as inflammation [33, 201-202].

miRNAs-Among all ncRNAs, miRNAs have been best studied and also are the most studied ncRNA in persistent pain conditions [203-208]. Initially, it is believed that only eukaryotes express miRNA, but recent data indicate that prokaryotes may also utilize this mechanism [209]. Eukaryotic genomes encode miRNAs with thousand of genes that are intergenic, intronic or exonic (only from large ncRNA genes) for single or in clusters of products [209-210]. Transcription of miRNA genes may be controlled by host gene promoters or by their own promoters, individually or in cluster, by RNA polymerase II, or III in some cases, in a tissue or cell specific manner [199-200, 210]. Pri-miRNAs are the immediate transcripts with the average size of 100 1000 n.t. or larger and undergoes cleavage on the microprocessor complex into shortened stem-loop pre-miRNAs (60 100 n.t.) that are exported out the nucleus and further cleaved into matured and small singlestranded miRNA (16 29 n.t.) mostly on the Dicer oriented complex in the cytoplasm [199200, 209-210]. Only mature miRNAs are the functional molecules acting on the 3' untranslated regions of target mRNAs on the RNA-induced silencing complex and reducing mRNA stability and/or translation rate [202, 209]. It has been known from computer algorithms based on experimental data that one mature miRNA may target more than one hundred mRNAs and, conversely, one given mRNA may contain multiple potential sites for the same and/or different miRNAs [211]. According to the latest V20 release from the Sanger's miRBase the numbers of miRNA genes and mature molecules are 1872/2578, $1186 / 1908$ and 449/728 for human, mouse and rat, respectively [212]. Based on the facts above, to be functional, miRNA and its mRNA target(s) must be co-localized in the same cell. Technically, due to the short sequence of mature miRNA, the method applied to studies is critical for reliable and specific quantification [213].

Several groups including us have performed initial studies of miRNA in persistent pain conditions. We applied mature miRNA-specific Taqman qRT-PCR and found that expression of several mature miRNAs (miR-10a, -29a, -98, -99a, -124a, -134, and -183) in the mandibular division of the trigeminal ganglion (TG) were downregulated following masseter muscle inflammation induced by CFA, and the downregulation was associated with the development of mechanical allodynia [214]. Since then, expression of miRNAs in tissues processing pain under various persistent pain conditions has been scrutinized by many laboratories. In most cases miRNA downregulation was found from body fluids including CSF of female patients with fibromyalgia [215] and blood or serum of patients with complex regional pain syndrome [216] and osteoarthritis of the knee and hip joints [217], and tissues of DRG/TG [214, 218-225, 244], the spinal cord [220, 224, 226-227], brain regions [228] and keratinocytes [229] in the early stage of persistent pain [214] or at the later stage $[218,228]$. Smaller numbers of miRNAs were found to be upregulated in the circulation of complex regional pain syndrome [216] and IBS patients [230], DRG [221, 
$231,244]$, and the spinal cord [219, 232] under various persistent pain conditions. Abnormal expression profile of miRNAs was found in DRG of bone cancer pain [233] and osteoarthritis rats [224], the spinal cord of CCI rats [226, 234] and osteoarthritis rats [224], hippocampi in CFA and CCI rats [235], CSF of females with fibromyalgia [215], or compared with that of mRNAs in hippocampus after CCI [236]. Using in situ hybridization, a number of laboratories have identified neuronal miRNAs in DRG or in the spinal cord $[218,222-223,225,231,237]$ and glial miRNAs in the spinal cord [227, 232]. We will discuss only those with convincing evidence of miRNA-target relationship or miRNAnociceptive responses, which is also summarized in table 3 . The altered expression of miRNAs under pain conditions and potential contribution of several miRNA species to persistent pain due to their involvements in neuronal plasticity and homeostasis as well as regulation of pain genes have been reviewed by others recently [203-208].

Using conditional knock-out of Dicer, the critical protein in production of mature miRNA from stem-loop pre-miRNA, in mouse sensory neurons expressing Nav1.8, Zhao et al. observed that animals exhibited a normal nociceptive response but less sensitivity to develop inflammatory pain, thus indicating the importance of maturation of most miRNAs to develop inflammatory hypersensitivity [238]. Meanwhile, DRG cells in Dicer null animals had upregulation of many generally expressed mRNAs while expressed less mRNAs of Nav1.8, P2xr3 and Runx-1. Because a few of the miRNA species may be matured via bypassing Dicer, these miRNAs are expected to play unimportant roles in nociceptive sensitivity [199, 209].

A number of groups took various approaches to manipulate the level of selected miRNA(s) and modify persistent pain conditions. Sakai et al. found that miR-7a was downregulated in DRG in the late phase of SNL or CCI rats. Restoring expression of miR-7a via locally injected AAV vector to DRG, they were able to reduce thermal and mechanical hypersensitivity and identified a potential target, the $\beta 2$ subunit of the voltage-gated sodium channel [223]. Interestingly, they failed to alter inflammatory hypersensitivity induced by CFA. In contrast, no difference of miRNA expression profile was observed in the hippocampus between CCI and CFA rats [235]. Again in DRG neurons, Chen et al. found that downregulation of miR-96 was accompanied by an increase in Nav1.3 in DRG of CCI rats [239]. They confirmed this miRNA-target relationship in cultured embryonic DRG neurons by transfecting cells with miR-96 mimic and analyzing Nav1.3 mRNA levels. Importantly, they were able to attenuate CCI-induced hypersensitivity by intrathecal injection of this mimic, demonstrating analgesic effect of manipulating selected miRNA. Ni et al. observed a positive correlation between downregulated miR-134 and upregulated MOR mRNA in DRG of rats receiving CFA injection to their hindpaws [225]. Using transfection of cultured cell lines they further confirmed that MOR mRNA was the target of miR-134 although no hypersensitivity in animals was examined.

Shi et al. found that miR-195 was stably upregulated in the spinal cord since the early stage of SNL in rats [232]. They demonstrated that microglial cells were the responsive cells and blocking miR-195 with an inhibitor increased autophagy activation of microglial cells, producing an analgesic effect while miR-195 mimic enhanced mechanical and cold hypersensitivity induced by peripheral nerve injury. Their findings support the hypothesis 
that activation of microglia cells in the spinal cord is pronociceptive. In line with this study, another laboratory investigated the analgesic role of miR-124 by maintaining spinal microglia/macrophages in a quiescent state [227]. Their data showed that reduction of miR-124 in microglia isolated from the spinal cord was associated with a transition from acute to chronic hyperalgesia induced by IL-1 $\beta$ in LysM-GRK2+/- mice, in which a switch towards a pro-inflammatory phenotype together with increased pro-inflammatory cytokine occurred. Intrathecal miR-124 completely prevented this transition and was able to reverse the persistent hyperalgesia induced by carrageenan and prevent the development of mechanical allodynia in the spared nerve injury model of chronic neuropathic pain in wildtype mice. This study provided not only supportive evidence of the importance of microglial activation during the transition from acute to chronic pain, but also a potential analgesic approach. The role of neuronal miR-124 was not studied in this report even though spinal neurons express much higher miR-124 than glia and will receive treatment of intrathecal administration of either miR-124 mimic or inhibitor. A recent study of an acute inflammatory pain model of formalin, however, explored the role of miR-124 (or miR-124a) in the spinal neurons [240]. In this study, Kynast and colleagues reported that formalin injection into the dorsal hindpaw of mice led to downregulation of miR-124 in the spinal dorsal horn neurons although in lamina II neurons surrounded by IB4 ${ }^{+}$fibers following acute hypersensitivity [240]. Intravenous injection of miR-124 antisense (inhibitor) facilitated the formalin's response and increased mRNAs of a number of proinflammatory genes afterwards while miR-124 mimic attenuated formalin-induced acute hypersensitivity and reduced only MeCP2 and BDNF mRNAs in naïve animals. However, whether the expression of miR-124 and these mRNAs mediates formalin's effect on nociception is an unanswered question since pre-injected miR-124 inhibitor or mimic altered formalininduced hypersensitivity before any change of expression can be seen. The issue that miR-124 downregulation occurs in neurons rather than in glial cells seen in neuropathic pain may suggest different mechanisms underlying these pain conditions. In addition, all studies above examined only the mature miR-124 which is produced from precursors transcribed from three different genes [212]. It remains to be clarified how individual miR-124 genes contribute to the change of mature miR-124 in spinal neurons and glia for acute and neuropathic pain, respectively. Also at the spinal level, Favereaux et al. found that miR-103 was downregulated in the spinal dorsal horn of SNL rats and meanwhile expression of Cav1.2-comprising the L-type calcium channel (Cav1.2-LTC) was upregulated [237]. They found evidence that this miR-103 regulated the translation of three different subunits forming Cav1.2-LTC. Intrathecal administration of the miR-103 mimic significantly reduced hypersensitivity induced by SNL.

In diabetic peripheral neuropathy mice, Wang et al. discovered that hyperglycemia downregulated miR-146a, but elevated levels of interleukin-1 receptor-activated kinase and tumor necrosis factor receptorassociated factor 6 in DRG neurons [241]. They provided evidence that treating diabetic peripheral neuropathy with a phosphodiesterase 5 inhibitor reversed these changes and reduced cell death although no nociceptive response was examined from these mice. 
Other ncRNAs-Our knowledge of other ncRNAs in addition to miRNAs in nociceptive signaling and persistent pain is negligible except for one report published by Nature Neuroscience last year [242]. In this report, Tao's lab showed convincing evidence that naturally occurring antisense RNA as long ncRNA overlapping mRNA sequences of the voltage-gated $\mathrm{K}^{+}$channel Kcna2 (Kv1.2) was expressed in DRG and its expression was induced in rats after SNL. This antisense RNA was expressed in about $21 \%$ of DRG neurons, of which $24 \%$ are small, $69 \%$ medium, and $7 \%$ large cells. In almost all antisense RNA-expressing neurons, there was a very low level of Kcna2. Forced expression of this antisense RNA resulted in reduced total voltage-gated potassium current, increased excitability in DRG neurons and produced neuropathic pain in naive animals. Their studies inform us that long ncRNAs regulate gene expression via epigenetic mechanisms not only in cancer cells, but also in the neural cells processing pain.

\section{Closing remarks}

We believe that epigenetic mechanisms actively participate in the development, maintenance and possibly transition of acute to the chronic phase of persistent pain and thus have potential value in translational medicine. There are many questions or challenges remaining to be addressed. For example, what is the overall impact and details within these mechanisms on persistent pain? The balance of sophisticated and dynamic gene expression plays critical roles in maintain cellular homeostasis. From all studies of gene expression involving pain, we believe that the balance between pro-nociceptive genes and antinociceptive genes in cells processing pain determines the pain condition. Various epigenetic mechanisms participate in maintaining this balance. For examples, increased histone acetylation may be analgesic under one chronic pain condition [146-147], but could facilitate nociception under another chronic pain condition [160]. HDACi treatment may upregulate one set of genes, but downregulate another set of genes in the CNS [191-193]. Therefore, the local or gene specific regulation for groups of genes is a more critical issue in understanding epigenetic regulation of nociception. Although we have gained some understanding of miRNA in persistent pain, the mutual multiple relationships between miRNA and mRNA targets is not well understood, which is critical for translation medicine in the future. Four drugs inhibiting DNMT or HDAC have been approved by the U.S. FDA for treatment of cancers [243]. We expect that the future studies of epigenetic mechanisms may produce novel and effective analgesic drugs for human health care.

\section{Acknowledgment(s)}

We appreciate Dr. Richard J. Traub for reading and discussion of the section regarding visceral pain. This review is supported by NIH grants NS060735 and DE021804. The following statements are in accordance with Journal policy. 1) None of the authors has any financial or personal relationship with organizations that could potentially be perceived as influencing the described research. 2) All authors have read the journal's policy and have not disclosed any potential conflict of interest. 3) No editorial support was used for preparation of the manuscript. All authors have read the Journal's authorship agreement

\section{Abbreviations}

acH3 acetylated histone 3 


$\begin{array}{ll}\text { acH4 } & \text { acetylated histone } 4 \\ \text { CCI } & \text { chronic constriction injury } \\ \text { CGI } & \text { CpG island } \\ \text { DNMT } & \text { DNA methyltransferase } \\ \text { DRG } & \text { dorsal root ganglion } \\ \text { GWAS } & \text { genome-wide association studies } \\ \text { HAT } & \text { Histone acetyltransferase } \\ \text { HATi } & \text { HAT inhibitor } \\ \text { HDAC } & \text { Histone deacetylase } \\ \text { HDACi } & \text { HDAC inhibitor } \\ \text { 5mC } & \text { 5-methylated cytosine } \\ \text { MT } & \text { morphine tolerance } \\ \text { ncRNA } & \text { non-coding RNA } \\ \text { PSL } & \text { partial sciatic nerve ligation } \\ \text { SCN } & \text { sciatic nerve } \\ \text { SNPs } & \text { single nucleotide polymorphisms } \\ \text { SNL } & \text { spinal nerve ligation } \\ \text { TSS } & \text { transcription start sites } \\ & \end{array}$

\section{References}

[1]. Goldberg D, McGee S. Pain as a global public health priority. BMC Public Health. 2011; 11:770. [PubMed: 21978149]

[2]. Campbell J, Meyer R. Mechanisms of neuropathic pain. Neuron. 2006; 52:77-92. [PubMed: 17015228]

[3]. Breivik H, Collett B, Ventafridda V, Cohen R, Gallacher D. Survey of chronic pain in Europe: prevalence, impact on daily life, and treatment. Eur J Pain. 2006; 10:287-333. [PubMed: 16095934]

[4]. Goodman J, McGrath P. The epidemiology of pain in children and adolescents: a review. Pain. 1991; 46:247-64. [PubMed: 1758709]

[5]. Johannes CB, Le TK, Zhou X, Johnston JA, Dworkin RH. The Prevalence of Chronic Pain in United States Adults: Results of an Internet-Based Survey. J Pain. 2010; 11:1230-9. [PubMed: 20797916]

[6]. Tsang A, Von Korff M, Lee S, Alonso J, Karam E, Angermeyer MC, et al. Common Chronic Pain Conditions in Developed and Developing Countries: Gender and Age Differences and Comorbidity With Depression-Anxiety Disorders. J Pain. 2008; 9:883-91. [PubMed: 18602869]

[7]. Apkarian AV, Baliki MN, Geha PY. Towards a theory of chronic pain. Prog Neurobiol. 2009; 87:81-97. [PubMed: 18952143]

[8]. van Hecke O, Torrance N, Smith BH. Chronic pain epidemiology and its clinical relevance. Brit J Anaesth. 2013; 111:13-8. [PubMed: 23794640]

Transl Res. Author manuscript; available in PMC 2016 January 01. 
[9]. Nielsen CS, Staud R, Price DD. Individual Differences in Pain Sensitivity: Measurement, Causation, and Consequences. J Pain. 2009; 10:231-7. [PubMed: 19185545]

[10]. Denk F, McMahon SB, Tracey I. Pain vulnerability: a neurobiological perspective. Nat Neurosci. 2014; 17:192-200. [PubMed: 24473267]

[11]. Woolf CJ, Salter MW. Neuronal Plasticity: Increasing the Gain in Pain. Science. 2000; 288:1765-8. [PubMed: 10846153]

[12]. Cooke SF, Bliss TVP. Plasticity in the human central nervous system. Brain. 2006; 129:1659-73. [PubMed: 16672292]

[13]. Bie B, Brown DL, Naguib M. Synaptic plasticity and pain aversion. Eur J Pharmacol. 2011; 667:26-31. [PubMed: 21699892]

[14]. Dubner R. The neurobiology of persistent pain and its clinical implications. Suppl Clin Neurophysiol. 2004; 57:3-7. [PubMed: 16106600]

[15]. Basbaum A, Bautista D, Scherrer G, Julius D. Cellular and molecular mechanisms of pain. Cell. 2009; 139:267-84. [PubMed: 19837031]

[16]. Ren K, Dubner R. Neuron-glia crosstalk gets serious: role in pain hypersensitivity. Curr Opin Anaesthesiol. 2008; 21:570-9. [PubMed: 18784481]

[17]. Ren K, Novikova SI, He F, Dubner R, Lidow MS. Neonatal local noxious insult affects gene expression in the spinal dorsal horn of adult rats. Mol Pain. 2005; 1:27. [PubMed: 16179088]

[18]. Yukhananov R, Kissin I. Persistent changes in spinal cord gene expression after recovery from inflammatory hyperalgesia: A preliminary study on pain memory. BMC Neurosci. 2008; 9:32. [PubMed: 18366630]

[19]. Woolf CJ, Costigan M. Transcriptional and posttranslational plasticity and the generation of inflammatory pain. Proc Natl Acad Sci U S A. 1999; 96:7723-30. [PubMed: 10393888]

[20]. Griffin RS, Costigan M, Brenner GJ, Ma CH, Scholz J, Moss A, et al. Complement induction in spinal cord microglia results in anaphylatoxin C5a-mediated pain hypersensitivity. J Neurosci. 2007; 27:8699-708. [PubMed: 17687047]

[21]. Geranton SM, Morenilla-Palao C, Hunt SP. A role for transcriptional repressor methyl-CpGbinding protein 2 and plasticity-related gene serum- and glucocorticoid-inducible kinase 1 in the induction of inflammatory pain states. J Neurosci. 2007; 27:6163-73. [PubMed: 17553988]

[22]. Lacroix-Fralish ML, Ledoux JB, Mogil JS. The Pain Genes Database: An interactive web browser of pain-related transgenic knockout studies. Pain. 2007; 131:3, e1-4. [PubMed: 17574758]

[23]. Lacroix-Fralish ML, Tawfik VL, Tanga FY, Spratt KF, DeLeo JA. Differential spinal cord gene expression in rodent models of radicular and neuropathic pain. Anesthesiology. 2006; 104:128392. [PubMed: 16732101]

[24]. Tsuda M, Masuda T, Tozaki-Saitoh H, Inoue K. Microglial regulation of neuropathic pain. J Pharmacol Sci. 2013; 121:89-94. [PubMed: 23337437]

[25]. Kim H, Mittal DP, Iadarola MJ, Dionne RA. Genetic predictors for acute experimental cold and heat pain sensitivity in humans. J Med Genet. 2006; 43:e40. [PubMed: 16882734]

[26]. Drenth JP, Waxman SG. Mutations in sodium-channel gene SCN9A cause a spectrum of human genetic pain disorders. J Clin Invest. 2007; 117:3603-9. [PubMed: 18060017]

[27]. Reimann F, Cox JJ, Belfer I, Diatchenko L, Zaykin DV, McHale DP, et al. Pain perception is altered by a nucleotide polymorphism in SCN9A. Proc Natl Acad Sci U S A. 2010; 107:5148-53. [PubMed: 20212137]

[28]. Musselman CA, Lalonde ME, Cote J, Kutateladze TG. Perceiving the epigenetic landscape through histone readers. Nat Struct Mol Biol. 2012; 19:1218-27. [PubMed: 23211769]

[29]. Bonasio R, Tu S, Reinberg D. Molecular Signals of Epigenetic States. Science. 2010; 330:612-6. [PubMed: 21030644]

[30]. Suter M, Aagaard-Tillery K. Environmental influences on epigenetic profiles. Semin Reprod Med. 2009; 27:380-90. [PubMed: 19711248]

[31]. Suter M, Ma J, Harris A, Patterson L, Brown K, Shope C, et al. Maternal tobacco use modestly alters correlated epigenome-wide placental DNA methylation and gene expression. Epigenetics. 2011; 6:1284-94. [PubMed: 21937876]

Transl Res. Author manuscript; available in PMC 2016 January 01. 
[32]. Blancafort P, Jin J, Frye S. Writing and Rewriting the Epigenetic Code of Cancer Cells: From Engineered Proteins to Small Molecules. Mol Pharmacol. 2013; 83:563-76. [PubMed: 23150486]

[33]. Kaikkonen MU, Lam MTY, Glass CK. Non-coding RNAs as regulators of gene expression and epigenetics. Cardiovasc Res. 2011; 90:430-40. [PubMed: 21558279]

[34]. Deaton, AeM; Bird, A. CpG islands and the regulation of transcription. Genes Dev. 2011; 25:1010-22. [PubMed: 21576262]

[35]. Abel T, Zukin RS. Epigenetic targets of HDAC inhibition in neurodegenerative and psychiatric disorders. Curr Opin Pharmacol. 2008; 8:57-64. [PubMed: 18206423]

[36]. Borrelli E, Nestler EJ, Allis CD, Sassone-Corsi P. Decoding the Epigenetic Language of Neuronal Plasticity. Neuron. 2008; 60:961-74. [PubMed: 19109904]

[37]. Sweatt JD. Experience-dependent epigenetic modifications in the central nervous system. Biol Psychiatry. 2009; 65:191-7. [PubMed: 19006788]

[38]. Ren K, Anseloni V, Zou SP, Wade EB, Novikova SI, Ennis M, et al. Characterization of basal and reinflammation-associated long-term alteration in pain responsivity following short-lasting neonatal local inflammatory insult. Pain. 2004; 110:588-96. [PubMed: 15288399]

[39]. Sun Y, Liang D, Sahbaie P, Clark JD. Effects of Methyl Donor Diets on Incisional Pain in Mice. PLoS ONE. 2013; 8:e77881. [PubMed: 24205011]

[40]. Fejer R, Hartvigsen J, Kyvik KO. Heritability of neck pain: a population-based study of 33794 Danish twins. Rheumatology. 2006; 45:589-94. [PubMed: 16332950]

[41]. Angst MS, Phillips NG, Drover DR, Tingle M, Ray A, Swan GE, et al. Pain sensitivity and opioid analgesia: A pharmacogenomic twin study. Pain. 2012; 153:1397-409. [PubMed: 22444188]

[42]. Norbury TA, MacGregor AJ, Urwin J, Spector TD, McMahon SB. Heritability of responses to painful stimuli in women: a classical twin study. Brain. 2007; 130:3041-9. [PubMed: 17932101]

[43]. Suter MA, Anders AM, Aagaard KM. Maternal smoking as a model for environmental epigenetic changes affecting birthweight and fetal programming. Mol Hum Reprod. 2013; 19:1-6. [PubMed: 23139402]

[44]. Mitchell MD, Mannino DM, Steinke DT, Kryscio RJ, Bush HM, Crofford LJ. Association of Smoking and Chronic Pain Syndromes in Kentucky Women. J Pain. 2011; 12:892-9. [PubMed: 21816352]

[45]. Compton P, Canamar CP, Hillhouse M, Ling W. Hyperalgesia in heroin dependent patients and the effects of opioid substitution therapy. J Pain. 2012; 13:401-9. [PubMed: 22424799]

[46]. Wang LX, Wang ZJ. Animal and cellular models of chronic pain. Adv Drug Del Rev. 2003; 55:949-65.

[47]. Benoliel R, Epstein J, Eliav E, Jurevic R, Elad S. Orofacial Pain in Cancer: Part I--Mechanisms. J Dent Res. 2007; 86:491-505. [PubMed: 17525348]

[48]. Villeneuve LM, Natarajan R. The role of epigenetics in the pathology of diabetic complications. Am J Physiol Renal Physiol. 2010; 299:F14-25. [PubMed: 20462972]

[49]. Chiechio S, Nicoletti F. Metabotropic glutamate receptors and the control of chronic pain. Curr Opin Pharmacol. 2012; 12:28-34. [PubMed: 22040745]

[50]. Denk F, McMahon Stephen B. Chronic Pain: Emerging Evidence for the Involvement of Epigenetics. Neuron. 2012; 73:435-44. [PubMed: 22325197]

[51]. Doehring A, Geisslinger G, Lotsch J. Epigenetics in pain and analgesia: an imminent research field. Eur J Pain. 2011; 15:11-6. [PubMed: 20584621]

[52]. Rahn EJ, Guzman-Karlsson MC, David Sweatt J. Cellular, molecular, and epigenetic mechanisms in non-associative conditioning: Implications for pain and memory. Neurobiol Learn Mem. 2013; 105:133-50. [PubMed: 23796633]

[53]. Mogil JS. Pain genetics: past, present and future. Trends Genet. 2012; 28:258-66. [PubMed: 22464640]

[54]. Buchheit T, Van de Ven T, Shaw A. Epigenetics and the Transition from Acute to Chronic Pain. Pain Med. 2012; 13:1474-90. [PubMed: 22978429]

Transl Res. Author manuscript; available in PMC 2016 January 01. 
[55]. Bird A. The Dinucleotide CG as a Genomic Signalling Module. J Mol Biol. 2011; 409:47-53. [PubMed: 21295585]

[56]. Varela M, Roberts T, Wood MA. Epigenetics and ncRNAs in Brain Function and Disease: Mechanisms and Prospects for Therapy. Neurotherapeutics. 2013; 10:621-31. [PubMed: 24068583]

[57]. Mehler MF. Epigenetic principles and mechanisms underlying nervous system functions in health and disease. Prog Neurobiol. 2008; 86:305-41. [PubMed: 18940229]

[58]. Holliday R, Pugh J. DNA modification mechanisms and gene activity during development. Science. 1975; 187:226-32. [PubMed: 1111098]

[59]. Riggs A. X inactivation, differentiation, and DNA methylation. Cytogenet Cell Genet. 1975; 14:9-25. [PubMed: 1093816]

[60]. Lan J, Hua S, He X, Zhang Y. DNA methyltransferases and methyl-binding proteins of mammals. Acta Bioch Bioph Sin. 2010; 42:243-52.

[61]. Bird A. DNA methylation patterns and epigenetic memory. Genes Dev. 2002; 16:6-21. [PubMed: 11782440]

[62]. Hendrich B, Tweedie S. The methyl-CpG binding domain and the evolving role of DNA methylation in animals. Trends Genet. 2003; 19:269-77. [PubMed: 12711219]

[63]. Sasaki H, Ishihara K, Kato R. Mechanisms of Igf2/H19 Imprinting: DNA Methylation, Chromatin and Long-Distance Gene Regulation. J Biochem. 2000; 127:711-5. [PubMed: 10788777]

[64]. Reik W, Walter J. Evolution of imprinting mechanisms: the battle of the sexes begins in the zygote. Nat Genet. 2001; 27:255-6. [PubMed: 11242103]

[65]. Gardiner-Garden M, Frommer M. CpG islands in vertebrate genomes. J Mol Biol. 1987; 196:261-82. [PubMed: 3656447]

[66]. Saxonov S, Berg P, Brutlag DL. A genome-wide analysis of CpG dinucleotides in the human genome distinguishes two distinct classes of promoters. Proc Natl Acad Sci U S A. 2006; 103:1412-7. [PubMed: 16432200]

[67]. Illingworth RS, Bird AP. CpG islands - `A rough guide'. FEBS Lett. 2009; 583:1713-20. [PubMed: 19376112]

[68]. Marino-Ramirez L, Spouge JL, Kanga GC, Landsman D. Statistical analysis of over-represented words in human promoter sequences. Nucl Acids Res. 2004; 32:949-58. [PubMed: 14963262]

[69]. Davuluri RV, Grosse I, Zhang MQ. Computational identification of promoters and first exons in the human genome. Nat Genet. 2001; 29:412-7. [PubMed: 11726928]

[70]. Illingworth R, Kerr A, DeSousa D, Jørgensen H, Ellis P, Stalker J, et al. A Novel CpG Island Set Identifies Tissue-Specific Methylation at Developmental Gene Loci. PLoS Biol. 2008; 6:e22. [PubMed: 18232738]

[71]. Venter JC, Adams MD, Myers EW, Li PW, Mural RJ, Sutton GG, et al. The sequence of the human genome. Science. 2001; 291:1304-51. [PubMed: 11181995]

[72]. Lander ES, Linton LM, Birren B, Nusbaum C, Zody MC, Baldwin J, et al. Initial sequencing and analysis of the human genome. Nature. 2001; 409:860-921. [PubMed: 11237011]

[73]. Irizarry R, Ladd-Acosta C, Wen B, Wu Z, Montano C, Onyango P, et al. The human colon cancer methylome shows similar hypo- and hypermethylation at conserved tissue-specific $\mathrm{CpG}$ island shores. Nat Genet. 2009; 41:178-86. [PubMed: 19151715]

[74]. Robinson MD, Stirzaker C, Statham AL, Coolen MW, Song JZ, Nair SS, et al. Evaluation of affinity-based genome-wide DNA methylation data: Effects of $\mathrm{CpG}$ density, amplification bias, and copy number variation. Genome Res. 2010; 20:1719-29. [PubMed: 21045081]

[75]. Hackenberg M, Previti C, Luque-Escamilla P, Carpena P, Martinez-Aroza J, Oliver J. CpGcluster: a distance-based algorithm for CpG-island detection. BMC Bioinformatics. 2006; 7:446. [PubMed: 17038168]

[76]. Chahrour M, Jung SY, Shaw C, Zhou X, Wong ST, Qin J, et al. MeCP2, a key contributor to neurological disease, activates and represses transcription. Science. 2008; 320:1224-9. [PubMed: 18511691] 
[77]. Song F, Smith JF, Kimura MT, Morrow AD, Matsuyama T, Nagase H, et al. Association of tissue-specific differentially methylated regions (TDMs) with differential gene expression. Proc Natl Acad Sci U S A. 2005; 102:3336-41. [PubMed: 15728362]

[78]. Wu X, Rauch TA, Zhong X, Bennett WP, Latif F, Krex D, et al. CpG Island Hypermethylation in Human Astrocytomas. Cancer Res. 2010; 70:2718-27. [PubMed: 20233874]

[79]. Nagae G, Isagawa T, Shiraki N, Fujita T, Yamamoto S, Tsutsumi S, et al. Tissue-specific demethylation in CpG-poor promoters during cellular differentiation. Hum Mol Genet. 2011; 20:2710-21. [PubMed: 21505077]

[80]. Fouse SD, Shen Y, Pellegrini M, Cole S, Meissner A, Van Neste L, et al. Promoter CpG Methylation Contributes to ES Cell Gene Regulation in Parallel with Oct4/Nanog, PcG Complex, and Histone H3 K4/K27 Trimethylation. Cell Stem Cell. 2008; 2:160-9. [PubMed: 18371437]

[81]. McGraw S, Shojaei Saadi HA, Robert C. Meeting the methodological challenges in molecular mapping of the embryonic epigenome. Mol Hum Reprod. 2013; 19:809-27. [PubMed: 23783346]

[82]. Shen L, Waterland RA. Methods of DNA methylation analysis. Curr Opin Clin Nutr Metab Care. 2007; 10:576-81. [PubMed: 17693740]

[83]. Ho SM, Tang WY. Techniques used in studies of epigenome dysregulation due to aberrant DNA methylation: an emphasis on fetal-based adult diseases. Reprod Toxicol. 2007; 23:267-82. [PubMed: 17317097]

[84]. Gupta R, Nagarajan A, Wajapeyee N. Advances in genome-wide DNA methylation analysis. Biotechniques. 2010; 49:iii-xi. [PubMed: 20964631]

[85]. Tajerian M, Alvarado S, Millecamps M, Dashwood T, Anderson KM, Haglund L, et al. DNA methylation of SPARC and chronic low back pain. Mol Pain. 2011; 7:65. [PubMed: 21867537]

[86]. Tajerian M, Alvarado S, Millecamps M, Vachon P, Crosby C, Bushnell MC, et al. Peripheral Nerve Injury Is Associated with Chronic, Reversible Changes in Global DNA Methylation in the Mouse Prefrontal Cortex. PLoS ONE. 2013; 8:e55259. [PubMed: 23383129]

[87]. Wang Y, Liu C, Guo Q-L, Yan J-Q, Zhu X-Y, Huang C-S, et al. Intrathecal 5-azacytidine inhibits global DNA methylation and methyl- CpG-binding protein 2 expression and alleviates neuropathic pain in rats following chronic constriction injury. Brain Res. 2011; 1418:64-9. [PubMed: 21925646]

[88]. Bai G, Guo W, Wei D, Zou S, Ren K, Dubner R. The role of spinal de novo DNA methylation in the development of inflammatory pain Soc Neurosci. 2008; 468:10.

[89]. Qi F, Zhou Y, Xiao Y, Tao J, Gu J, Jiang X, et al. Promoter demethylation of cystathionine-betasynthetase gene contributes to inflammatory pain in rats. Pain. 2013; 154:34-45. [PubMed: 23273102]

[90]. Zhang H, Hu J, Zhou Y, Hu S, Wang Y, Chen W, et al. Promoted interaction of nuclear factorkappaB with demethylated cystathionine-beta-synthetase gene contributes to gastric hypersensitivity in diabetic rats. J Neurosci. 2013; 33:9028-38. [PubMed: 23699514]

[91]. Bell JT, Loomis AK, Butcher LM, Gao F, Zhang B, Hyde CL, et al. Differential methylation of the TRPA1 promoter in pain sensitivity. Nat Commun. 2014; 5

[92]. Mbadiwe T, Millis RM. Epigenetics and autism. Autism Res Treat. 2013; 2013:826156. [PubMed: 24151554]

[93]. Gos M. Epigenetic mechanisms of gene expression regulation in neurological diseases. Acta Neurobiol Exp (Wars). 2013; 73:19-37. [PubMed: 23595281]

[94]. Geranton S, Fratto V, Tochiki K, Hunt S. Descending serotonergic controls regulate inflammation-induced mechanical sensitivity and methyl-CpG-binding protein 2 phosphorylation in the rat superficial dorsal horn. Mol Pain. 2008; 4:35. [PubMed: 18793388]

[95]. Dray A. Neuropathic pain: emerging treatments. Brit J Anaesth. 2008; 101:48-58. [PubMed: 18511441]

[96]. Hwang CK, Song KY, Kim CS, Choi HS, Guo X-H, Law P-Y, et al. Epigenetic programming of $\mu$-opioid receptor gene in mouse brain is regulated by MeCP2 and brg 1 chromatin remodelling factor. J Cell Mol Med. 2009; 13:3591-615. [PubMed: 19602036] 
[97]. Doehring A, Oertel BG, Sittl R, Lötsch J. Chronic opioid use is associated with increased DNA methylation correlating with increased clinical pain. Pain. 2013; 154:15-23. [PubMed: 23273101]

[98]. Kazazian HH Jr. Goodier JL. LINE drive. retrotransposition and genome instability. Cell. 2002; 110:277-80. [PubMed: 12176313]

[99]. Frigola J, Sole X, Paz MF, Moreno V, Esteller M, Capella G, et al. Differential DNA hypermethylation and hypomethylation signatures in colorectal cancer. Hum Mol Genet. 2005; 14:319-26. [PubMed: 15574462]

[100]. Liao LM, Brennan P, van Bemmel DM, Zaridze D, Matveev V, Janout V, et al. LINE-1 Methylation Levels in Leukocyte DNA and Risk of Renal Cell Cancer. PLoS ONE. 2011; 6:e27361. [PubMed: 22076155]

[101]. Doehring A, Oertel BG, Sittl R, Lotsch J. Chronic opioid use is associated with increased DNA methylation correlating with increased clinical pain. Pain. 2013; 154:15-23. [PubMed: 23273101]

[102]. Lister R, Mukamel EA, Nery JR, Urich M, Puddifoot CA, Johnson ND, et al. Global Epigenomic Reconfiguration During Mammalian Brain Development. Science. 2013; 341

[103]. Tran L, Chaloner A, Sawalha A, Greenwood Van-Mee B. Importance of epigenetic mechanisms in visceral pain induced by chronic water avoidance stress. Psychoneuroendocrinology. 2013; 38:898-906. [PubMed: 23084728]

[104]. Ren K, Dubner R. Pain facilitation and activity-dependent plasticity in pain modulatory circuitry: role of BDNF-TrkB signaling and NMDA receptors. Mol Neurobiol. 2007; 35:224-35. [PubMed: 17917111]

[105]. Calixto JB, Kassuya CA, Andre E, Ferreira J. Contribution of natural products to the discovery of the transient receptor potential (TRP) channels family and their functions. Pharmacol Ther. 2005; 106:179-208. [PubMed: 15866319]

[106]. Julius D. TRP channels and pain. Annu Rev Cell Dev Biol. 2013; 29:355-84. [PubMed: 24099085]

[107]. Fernandes ES, Fernandes MA, Keeble JE. The functions of TRPA1 and TRPV1: moving away from sensory nerves. Brit J Pharmacol. 2012; 166:510-21. [PubMed: 22233379]

[108]. Menzies V, Lyon DE, Archer KJ, Zhou Q, Brumelle J, Jones KH, et al. Epigenetic Alterations and an Increased Frequency of Micronuclei in Women with Fibromyalgia. Nursing Research and Practice. 2013; 2013:12.

[109]. Oertel BG, Doehring A, Roskam B, Kettner M, Hackmann N, Ferreiroes N, et al. Geneticepigenetic interaction modulates $\mu$-opioid receptor regulation. Hum Mol Genet. 2012

[110]. Viet CT, Schmidt BL. Biologic Mechanisms of Oral Cancer Pain and Implications for Clinical Therapy. J Dent Res. 2012; 91:447-53. [PubMed: 21972258]

[111]. Khodorova A, Navarro B, Jouaville LS, Murphy JE, Rice FL, Mazurkiewicz JE, et al. Endothelin-B receptor activation triggers an endogenous analgesic cascade at sites of peripheral injury. Nat Med. 2003; 9:1055-61. [PubMed: 12847519]

[112]. Piovezan AP, D'Orleans-Juste P, Souza GE, Rae GA. Endothelin-1-induced ET(A) receptormediated nociception, hyperalgesia and oedema in the mouse hind-paw: modulation by simultaneous ET(B) receptor activation. Br J Pharmacol. 2000; 129:961-8. [PubMed: 10696096]

[113]. Mantyh PW, Clohisy DR, Koltzenburg M, Hunt SP. Molecular mechanisms of cancer pain. Nat Rev Cancer. 2002; 2:201-9. [PubMed: 11990856]

[114]. Davies MN, Volta M, Pidsley R, Lunnon K, Dixit A, Lovestone S, et al. Functional annotation of the human brain methylome identifies tissue-specific epigenetic variation across brain and blood. Genome Biol. 2012; 13:R43. [PubMed: 22703893]

[115]. Penn NW, Suwalski R, O'Riley C, Bojanowski K, Yura R. The presence of 5hydroxymethylcytosine in animal deoxyribonucleic acid. Biochem J. 1972; 126:781-90. [PubMed: 4538516]

[116]. Ito S, Shen L, Dai Q, Wu SC, Collins LB, Swenberg JA, et al. Tet proteins can convert 5methylcytosine to 5-formylcytosine and 5-carboxylcytosine. Science. 2011; 333:1300-3. [PubMed: 21778364] 
[117]. Spruijt Cornelia G, Gnerlich F, Smits Arne H, Pfaffeneder T, Jansen Pascal WTC, Bauer C, et al. Dynamic Readers for 5-(Hydroxy)Methylcytosine and Its Oxidized Derivatives. Cell. 2013; 152:1146-59. [PubMed: 23434322]

[118]. Tahiliani M, Koh KP, Shen Y, Pastor WA, Bandukwala H, Brudno Y, et al. Conversion of 5Methylcytosine to 5-Hydroxymethylcytosine in Mammalian DNA by MLL Partner TET1. Science. 2009; 324:930-5. [PubMed: 19372391]

[119]. Kriaucionis S, Heintz N. The Nuclear DNA Base 5-Hydroxymethylcytosine Is Present in Purkinje Neurons and the Brain. Science. 2009; 324:929-30. [PubMed: 19372393]

[120]. Ito S, D/'Alessio AC, Taranova OV, Hong K, Sowers LC, Zhang Y. Role of Tet proteins in 5mC to $5 \mathrm{hmC}$ conversion, ES-cell self-renewal and inner cell mass specification. Nature. 2010; 466:1129-33. [PubMed: 20639862]

[121]. Khare T, Pai S, Koncevicius K, Pal M, Kriukiene E, Liutkeviciute Z, et al. 5-hmC in the brain is abundant in synaptic genes and shows differences at the exon-intron boundary. Nat Struct Mol Biol. 2012; 19:1037-43. [PubMed: 22961382]

[122]. Booth MJ, Branco MR, Ficz G, Oxley D, Krueger F, Reik W, et al. Quantitative Sequencing of 5-Methylcytosine and 5-Hydroxymethylcytosine at Single-Base Resolution. Science. 2012; 336:934-7. [PubMed: 22539555]

[123]. Yu M, Hon Gary C, Szulwach Keith E, Song C-X, Zhang L, Kim A, et al. Base-Resolution Analysis of 5-Hydroxymethylcytosine in the Mammalian Genome. Cell. 2012; 149:1368-80. [PubMed: 22608086]

[124]. Qu J, Zhou M, Song Q, Hong EE, Smith AD. MLML: consistent simultaneous estimates of DNA methylation and hydroxymethylation. Bioinformatics. 2013

[125]. Song CX, Szulwach KE, Fu Y, Dai Q, Yi C, Li X, et al. Selective chemical labeling reveals the genome-wide distribution of 5-hydroxymethylcytosine. Nat Biotechnol. 2011; 29:68-72. [PubMed: 21151123]

[126]. Szulwach KE, Li X, Li Y, Song CX, Wu H, Dai Q, et al. 5-hmC-mediated epigenetic dynamics during postnatal neurodevelopment and aging. Nat Neurosci. 2011; 14:1607-16. [PubMed: 22037496]

[127]. Iurlaro M, Ficz G, Oxley D, Raiber E-A, Bachman M, Booth M, et al. A screen for hydroxymethylcytosine and formylcytosine binding proteins suggests functions in transcription and chromatin regulation. Genome Biol. 2013; 14:R119. [PubMed: 24156278]

[128]. Yildirim O, Li R, Hung J-H, Chen Poshen B, Dong X, Ee L-S, et al. Mbd3/NURD Complex Regulates Expression of 5-Hydroxymethylcytosine Marked Genes in Embryonic Stem Cells. Cell. 2011; 147:1498-510. [PubMed: 22196727]

[129]. Mellén M, Ayata P, Dewell S, Kriaucionis S, Heintz N. MeCP2 Binds to 5hmC Enriched within Active Genes and Accessible Chromatin in the Nervous System. Cell. 2012; 151:1417-30. [PubMed: 23260135]

[130]. Valinluck V, Tsai H-H, Rogstad DK, Burdzy A, Bird A, Sowers LC. Oxidative damage to methyl-CpG sequences inhibits the binding of the methyl-CpG binding domain (MBD) of methyl-CpG binding protein 2 (MeCP2). Nucl Acids Res. 2004; 32:4100-8. [PubMed: 15302911]

[131]. Jenuwein T, Allis CD. Translating the Histone Code. Science. 2001; 293:1074-80. [PubMed: 11498575]

[132]. Strahl BD, Allis CD. The language of covalent histone modifications. Nature. 2000; 403:41-5. [PubMed: 10638745]

[133]. Ruthenburg A, Li H, Patel D, Allis C. Multivalent engagement of chromatin modifications by linked binding modules. Nat Rev Mol Cell Biol. 2007; 8:983-94. [PubMed: 18037899]

[134]. Tan M, Luo H, Lee S, Jin F, Yang Jeong S, Montellier E, et al. Identification of 67 Histone Marks and Histone Lysine Crotonylation as a New Type of Histone Modification. Cell. 2011; 146:1016-28. [PubMed: 21925322]

[135]. Ruthenburg A, Allis C, Wysocka J. Methylation of lysine 4 on histone H3: intricacy of writing and reading a single epigenetic mark. Mol Cell. 2007; 25:15-30. [PubMed: 17218268]

[136]. Kouzarides T. SnapShot: Histone-modifying enzymes. Cell. 2007; 131:822. [PubMed: 18022374]

Transl Res. Author manuscript; available in PMC 2016 January 01. 
[137]. Li S. Implication of posttranslational histone modifications in nucleotide excision repair. Int J Mol Sci. 2012; 13:12461-86. [PubMed: 23202908]

[138]. Shahbazian MD, Grunstein M. Functions of Site-Specific Histone Acetylation and Deacetylation. Annual Review of Biochemistry. 2007; 76:75-100.

[139]. Gregoretti I, Lee Y-M, Goodson HV. Molecular Evolution of the Histone Deacetylase Family: Functional Implications of Phylogenetic Analysis. J Med Chem. 2004; 338:17-31.

[140]. Gayatri S, Bedford MT. Readers of histone methylarginine marks. BBA- Gene Regul Mech. 2014

[141]. Mikkelsen T, Ku M, Jaffe D, Issac B, Lieberman E, Giannoukos G, et al. Genome-wide maps of chromatin state in pluripotent and lineage-committed cells. Nature. 2007; 448:553-60. [PubMed: 17603471]

[142]. Besant PG, Attwood PV. Histone H4 histidine phosphorylation: kinases, phosphatases, liver regeneration and cancer. Biochem Soc Trans. 2012; 40:290-3. [PubMed: 22260708]

[143]. Rossetto D, Avvakumov N, Cote J. Histone phosphorylation: a chromatin modification involved in diverse nuclear events. Epigenetics. 2012; 7:1098-108. [PubMed: 22948226]

[144]. Vojinovic J, Damjanov N. HDAC inhibition in rheumatoid arthritis and juvenile idiopathic arthritis. Mol Med. 2011; 17:397-403. [PubMed: 21308151]

[145]. Zhang Z-Y, Schluesener HJ. HDAC inhibitor MS-275 attenuates the inflammatory reaction in rat experimental autoimmune prostatitis. Prostate. 2012; 72:90-9. [PubMed: 21538420]

[146]. Zhang Z, Cai Y, Zou F, Bie B, Pan Z. Epigenetic suppression of GAD65 expression mediates persistent pain. Nat Med. 2011; 17:1448-55. [PubMed: 21983856]

[147]. Bai G, Wei D, Zou S, Ren K, Dubner R. Inhibition of class II histone deacetylases in the spinal cord attenuates inflammatory hyperalgesia. Mol Pain. 2010; 6:51. [PubMed: 20822541]

[148]. Marks PA, Richon VM, Rifkind RA. Histone Deacetylase Inhibitors: Inducers of Differentiation or Apoptosis of Transformed Cells. J Natl Cancer Inst. 2000; 92:1210-16. [PubMed: 10922406]

[149]. Milutinovic S, D'Alessio AC, Detich N, Szyf M. Valproate induces widespread epigenetic reprogramming which involves demethylation of specific genes. Carcinogenesis. 2007; 28:56071. [PubMed: 17012225]

[150]. Lundby A, Lage K, Weinert Brian T, Bekker-Jensen Dorte B, Secher A, Skovgaard T, et al. Proteomic Analysis of Lysine Acetylation Sites in Rat Tissues Reveals Organ Specificity and Subcellular Patterns. Cell Reports. 2012; 2:419-31. [PubMed: 22902405]

[151]. Wang L, Du Y, Lu M, Li T. ASEB: a web server for KAT-specific acetylation site prediction. Nucl Acids Res. 2012; 40:W376-W9. [PubMed: 22600735]

[152]. Consortium TU. Activities at the Universal Protein Resource (UniProt). Nucl Acids Res. 2014; 42:D191-D8. [PubMed: 24253303]

[153]. Kim MY, Woo EM, Chong YTE, Homenko DR, Kraus WL. Acetylation of Estrogen Receptor a by p300 at Lysines 266 and 268 Enhances the Deoxyribonucleic Acid Binding and Transactivation Activities of the Receptor. Mol Endocrinol. 2006; 20:1479-93. [PubMed: 16497729]

[154]. Ma Y, Fan S, Hu C, Meng Q, Fuqua SA, Pestell RG, et al. BRCA1 Regulates Acetylation and Ubiquitination of Estrogen Receptor-a. Mol Endocrinol. 2010; 24:76-90. [PubMed: 19887647]

[155]. Kiguchi N, Kobayashi Y, Maeda T, Fukazawa Y, Tohya K, Kimura M, et al. Epigenetic Augmentation of the Macrophage Inflammatory Protein 2/C-X-C Chemokine Receptor Type 2 Axis through Histone H3 Acetylation in Injured Peripheral Nerves Elicits Neuropathic Pain. J Pharmacol Exp Ther. 2012; 340:577-87. [PubMed: 22135382]

[156]. Kiguchi N, Kobayashi Y, Saika F, Kishioka S. Epigenetic upregulation of CCL2 and CCL3 via histone modifications in infiltrating macrophages after peripheral nerve injury. Cytokine. 2013; 64:666-72. [PubMed: 24135048]

[157]. Zhu X-Y, Huang C-S, Li Q, Chang R-m, Song Z-b, Zou W-y, et al. p300 exerts an epigenetic role in chronic neuropathic pain through its acetyltransferase activity in rats following chronic constriction injury (CCI). Mol Pain. 2012; 8:84. [PubMed: 23176208]

[158]. Roth S, Denu J, Allis C. Histone acetyltransferases. Annu Rev Biochem. 2001; 70:81-120. [PubMed: 11395403] 
[159]. Zhu X, Li Q, Chang R, Yang D, Song Z, Guo Q, et al. Curcumin Alleviates Neuropathic Pain by Inhibiting p300/CBP Histone Acetyltransferase Activity-Regulated Expression of BDNF and Cox-2 in a Rat Model. PLoS ONE. 2014; 9:e91303. [PubMed: 24603592]

[160]. Sun Y, Sahbaie P, Liang D-Y, Li W-W, Li X-Q, Shi X-Y, et al. Epigenetic Regulation of Spinal CXCR2 Signaling in Incisional Hypersensitivity in Mice. Anesthesiology. 2013; 119:1198-208. 10.097/ALN.0b013e31829ce340. [PubMed: 23756451]

[161]. Uchida H, Ma L, Ueda H. Epigenetic gene silencing underlies C-fiber dysfunctions in neuropathic pain. J Neurosci. 2010; 30:4806-14. [PubMed: 20357131]

[162]. Uchida H, Sasaki K, Ma L, Ueda H. Neuron-restrictive silencer factor causes epigenetic silencing of Kv4.3 gene after peripheral nerve injury. Neuroscience. 2010; 166:1-4. [PubMed: 20006971]

[163]. Ballas N, Mandel G. The many faces of REST oversee epigenetic programming of neuronal genes. Curr Opin Neurobiol. 2005; 15:500-6. [PubMed: 16150588]

[164]. Matsushita Y, Araki K, Omotuyi Oi, Mukae T, Ueda H. HDAC inhibitors restore C-fibre sensitivity in experimental neuropathic pain model. Brit J Pharmacol. 2013; 170:991-8. [PubMed: 24032674]

[165]. Uchida H, Matsushita Y, Ueda H. Epigenetic regulation of BDNF expression in the primary sensory neurons after peripheral nerve injury: Implications in the development of neuropathic pain. Neuroscience. 2013; 240:147-54. [PubMed: 23466809]

[166]. Cherng C-H, Lee K-C, Chien C-C, Chou K-Y, Cheng Y-C, Hsin S-T, et al. Baicalin ameliorates neuropathic pain by suppressing HDAC1 expression in the spinal cord of spinal nerve ligation rats. J Formos Med Assoc. 2014 Available online 16 May 2013.

[167]. Denk F, Huang W, Sidders B, Bithell A, Crow M, Grist J, et al. HDAC inhibitors attenuate the development of hypersensitivity in models of neuropathic pain. Pain. 2013; 154:1668-79. [PubMed: 23693161]

[168]. Johannessen CU, Johannessen SI. Valproate: past, present, and future. CNS Drug Rev. 2003; 9:199-216. [PubMed: 12847559]

[169]. Hobo S, Eisenach JC, Hayashida K-i. Up-regulation of spinal glutamate transporters contributes to anti-hypersensitive effects of valproate in rats after peripheral nerve injury. Neurosci Lett. 2011; 502:52-5. [PubMed: 21802494]

[170]. Yoshizumi M, Eisenach JC, Hayashida K-i. Valproate Prevents Dysregulation of Spinal Glutamate and Reduces the Development of Hypersensitivity in Rats After Peripheral Nerve Injury. J Pain. 2013; 14:1485-91. [PubMed: 24021575]

[171]. Kukkar A, Singh N, Jaggi AS. Attenuation of neuropathic pain by sodium butyrate in an experimental model of chronic constriction injury in rats. J Formos Med Assoc. 2014 Available online 16 July 2013.

[172]. Grayson DR, Kundakovic M, Sharma RP. Is There a Future for Histone Deacetylase Inhibitors in the Pharmacotherapy of Psychiatric Disorders? Mol Pharmacol. 2010; 77:126-35. [PubMed: 19917878]

[173]. Yin Q, Lu F-F, Zhao Y, Cheng M-Y, Fan Q, Cui J, et al. Resveratrol Facilitates Pain Attenuation in a Rat Model of Neuropathic Pain Through the Activation of Spinal Sirt1. Region Anesth Pain M. 2013; 38:93-9. 10.1097/AAP.0b013e3182795b23.

[174]. He X, Ou P, Wu K, Huang C, Wang Y, Yu Z, et al. Resveratrol attenuates morphine antinociceptive tolerance via SIRT1 regulation in the rat spinal cord. Neurosci Lett. 2014; 566:55-60. [PubMed: 24561089]

[175]. Tsai R-Y, Shen C-H, Feng Y-P, Chien C-C, Lee S-O, Tsai W-Y, et al. Ultra-low-dose naloxone enhances the antinociceptive effect of morphine in PTX-treated rats: Regulation on global histone methylation. Acta Anaesth Taiwanica. 2012; 50:106-11.

[176]. Imai S, Ikegami D, Yamashita A, Shimizu T, Narita M, Niikura K, et al. Epigenetic transcriptional activation of monocyte chemotactic protein 3 contributes to long-lasting neuropathic pain. Brain. 2013; 136:828-43. [PubMed: 23364351]

[177]. Lu Y, Nie J, Liu X, Zheng Y, Guo S-W. Trichostatin A, a histone deacetylase inhibitor, reduces lesion growth and hyperalgesia in experimentally induced endometriosis in mice. Hum Reprod. 2010; 25:1014-25. [PubMed: 20118114] 
[178]. Liu M, Liu X, Zhang Y, Guo S-W. Valproic Acid and Progestin Inhibit Lesion Growth and Reduce Hyperalgesia in Experimentally Induced Endometriosis in Rats. Reprod Sci. 2012; 19:360-73. [PubMed: 22344726]

[179]. Winston JH, Li Q, Sarna SK. Chronic prenatal stress epigenetically modifies spinal cord BDNF expression to induce sex-specific visceral hypersensitivity in offspring. Neurogastroenterol Motil. 2014; 4:12326.

[180]. Vaiopoulou A, Karamanolis G, Psaltopoulou T, Karatzias G, Gazouli M. Molecular basis of the irritable bowel syndrome. World J Gastroenterol. 2014; 20:376-83. [PubMed: 24574707]

[181]. Liang D-Y, Li X, Clark JD. Epigenetic Regulation of Opioid-Induced Hyperalgesia, Dependence, and Tolerance in Mice. J Pain. 2013; 14:36-47. [PubMed: 23273833]

[182]. Liu J, Liu F-Y, Tong Z-Q, Li Z-H, Chen W, Luo W-H, et al. Lysine-Specific Demethylase 1 in Breast Cancer Cells Contributes to the Production of Endogenous Formaldehyde in the Metastatic Bone Cancer Pain Model of Rats. PLoS ONE. 2013; 8:e58957. [PubMed: 23516587]

[183]. Liu AG, Hoffman PL, Zhuang ZY, Chai YF, Bai G. NF-kB site interacts with Sp factors and upregulates the NR1 promoter during neuronal differentiation. J Biol Chem. 2004; 279:1744958. [PubMed: 14970236]

[184]. Mayr B, Montminy M. Transcriptional regulation by the phosphorylation-dependent factor CREB. Nat Rev Mol Cell Biol. 2001; 2:599-609. [PubMed: 11483993]

[185]. Stenlund A, Botchan MR. The E2 trans-activator can act as a repressor by interfering with a cellular transcription factor. Genes Dev. 1990; 4:123-36. [PubMed: 2155158]

[186]. Inouye S, Fujimoto M, Nakamura T, Takaki E, Hayashida N, Hai T, et al. Heat Shock Transcription Factor 1 Opens Chromatin Structure of Interleukin-6 Promoter to Facilitate Binding of an Activator or a Repressor. J Biol Chem. 2007; 282:33210-7. [PubMed: 17766920]

[187]. Martínez-Montañés F, Rienzo A, Poveda-Huertes D, Pascual-Ahuir A, Proft M. Activator and Repressor Functions of the Mot3 Transcription Factor in the Osmostress Response of Saccharomyces cerevisiae. Eukaryotic Cell. 2013; 12:636-47. [PubMed: 23435728]

[188]. Choi CY, Lee YM, Kim YH, Park T, Jeon BH, Schulz RA, et al. The Homeodomain Transcription Factor NK-4 Acts as either a Transcriptional Activator or Repressor and Interacts with the p300 Coactivator and the Groucho Corepressor. J Biol Chem. 1999; 274:31543-52. [PubMed: 10531357]

[189]. Weill L, Shestakova E, Bonnefoy E. Transcription Factor YY1 Binds to the Murine Beta Interferon Promoter and Regulates Its Transcriptional Capacity with a Dual Activator/Repressor Role. J Virol. 2003; 77:2903-14. [PubMed: 12584314]

[190]. Kurdistani S, Tavazoie S, Grunstein M. Mapping global histone acetylation patterns to gene expression. Cell. 2004; 117:721-33. [PubMed: 15186774]

[191]. Ferrante RJ, Kubilus JK, Lee J, Ryu H, Beesen A, Zucker B, et al. Histone Deacetylase Inhibition by Sodium Butyrate Chemotherapy Ameliorates the Neurodegenerative Phenotype in Huntington's Disease Mice. J Neurosci. 2003; 23:9418-27. [PubMed: 14561870]

[192]. Covington HEI, Maze I, LaPlant QC, Vialou VF, Ohnishi YN, Berton O, et al. Antidepressant Actions of Histone Deacetylase Inhibitors. J Neurosci. 2009; 29:11451-60. [PubMed: 19759294]

[193]. Lopez-Atalaya JP, Ito S, Valor LM, Benito E, Barco A. Genomic targets, and histone acetylation and gene expression profiling of neural HDAC inhibition. Nucl Acids Res. 2013; 41:8072-84. [PubMed: 23821663]

[194]. Limbach PA, Crain PF, McCloskey JA. Summary: the modified nucleosides of RNA. Nucl Acids Res. 1994; 22:2183-96. [PubMed: 7518580]

[195]. Sharp PA. The Centrality of RNA. Cell. 2009; 136:577-80. [PubMed: 19239877]

[196]. ENCODE. Identification and analysis of functional elements in $1 \%$ of the human genome by the ENCODE pilot project. Nature. 2007; 447:799-816. [PubMed: 17571346]

[197]. Kapranov P, Willingham AT, Gingeras TR. Genome-wide transcription and the implications for genomic organization. Nat Rev Genet. 2007; 8:413-23. [PubMed: 17486121]

[198]. Kung JTY, Colognori D, Lee JT. Long Noncoding RNAs: Past, Present, and Future. Genetics. 2013; 193:651-69. [PubMed: 23463798]

[199]. Suzuki HI, Miyazono K. Emerging complexity of microRNA generation cascades. J Biochem. 2011; 149:15-25. [PubMed: 20876186] 
[200]. Treiber T, Treiber N, Meister G. Regulation of microRNA biogenesis and function. Thromb Haemost. 2012; 107

[201]. Lee JT. Epigenetic Regulation by Long Noncoding RNAs. Science. 2012; 338:1435-9. [PubMed: 23239728]

[202]. Rebane A, Akdis CA. MicroRNAs: Essential players in the regulation of inflammation. J Allergy Clin Immun. 2013; 132:15-26. [PubMed: 23726263]

[203]. Gheinani AH, Burkhard FC, Monastyrskaya K. Deciphering microRNA code in pain and inflammation: lessons from bladder pain syndrome. Cell Mol Life Sci. 2013; 70:3773-89. [PubMed: 23463234]

[204]. Elramah S, Landry M, Favereaux A. MicroRNAs regulate neuronal plasticity and are involved in pain mechanisms. Front Cell Neurosci. 2014; 8:31. [PubMed: 24574967]

[205]. Kress M, Huttenhofer A, Landry M, Kuner R, Favereaux A, Greenberg D, et al. microRNAs in nociceptive circuits as predictors of future clinical applications. Front Mol Neurosci. 2013; 6:33. [PubMed: 24151455]

[206]. Tan P-H, Pao Y-Y, Cheng J-K, Hung K-C, Liu C-C. MicroRNA-based therapy in pain medicine: Current progress and future prospects. Acta Anaesthesiologica Taiwanica. 2013; 51:171-6. [PubMed: 24529673]

[207]. Lutz BM, Bekker A, Tao YX. Noncoding RNAs: New Players in Chronic Pain. Anesthesiology. $2014 ; 15: 15$.

[208]. Kynast KL, Russe OQ, Geisslinger G, Niederberger E. Novel findings in pain processing pathways: implications for miRNAs as future therapeutic targets. Expert Rev Neurother. 2013; 13:515-25. [PubMed: 23621309]

[209]. Lee H-J. Exceptional stories of microRNAs. Experimental Biology and Medicine. 2013; 238:339-43. [PubMed: 23759998]

[210]. Kawahara H, Imai T, Okano H. MicroRNAs in neural stem cells and neurogenesis. Front Neurosci. 2012; 6

[211]. Bentwich I. Prediction and validation of microRNAs and their targets. FEBS Lett. 2005; 579:5904-10. [PubMed: 16214134]

[212]. Griffiths-Jones S, Saini HK, van Dongen S, Enright AJ. miRBase: tools for microRNA genomics. Nucl Acids Res. 2008; 36:D154-8. [PubMed: 17991681]

[213]. van Rooij E. The Art of MicroRNA Research. Circ Res. 2011; 108:219-34. [PubMed: 21252150]

[214]. Bai G, Ambalavanar R, Wei D, Dessem D. Downregulation of selective microRNAs in trigeminal ganglion neurons following inflammatory muscle pain. Mol Pain. 2007; 3:15. [PubMed: 17559665]

[215]. Bjersing JL, Lundborg C, Bokarewa MI, Mannerkorpi K. Profile of Cerebrospinal microRNAs in Fibromyalgia. PLoS ONE. 2013; 8:e78762. [PubMed: 24205312]

[216]. Orlova I, Alexander G, Qureshi R, Sacan A, Graziano A, Barrett J, et al. MicroRNA modulation in complex regional pain syndrome. J Transl Med. 2011; 9:195. [PubMed: 22074333]

[217]. Beyer, C.; Zampetaki, A.; Lin, N-Y.; Kleyer, A.; Perricone, C.; Iagnocco, A., et al. Annals of the Rheumatic Diseases. 2014. Signature of circulating microRNAs in osteoarthritis.

[218]. Aldrich B, Frakes E, Kasuya J, Hammond D, Kitamoto T. Changes in expression of sensory organ-specific microRNAs in rat dorsal root ganglia in association with mechanical hypersensitivity induced by spinal nerve ligation. Neuroscience. 2009; 164:711-23. [PubMed: 19699278]

[219]. Kusuda R, Cadetti F, Ravanelli M, Sousa T, Zanon S, De Lucca F, et al. Differential expression of microRNAs in mouse pain models. Mol Pain. 2011; 7:17. [PubMed: 21385380]

[220]. Li X, Gibson G, Kim J, Kroin J, Xu S, van Wijnen A, et al. MicroRNA-146a is linked to painrelated pathophysiology of osteoarthritis. Gene. 2011; 480:34-41. [PubMed: 21397669]

[221]. von Schack D, Agostino MJ, Murray BS, Li Y, Reddy PS, Chen J, et al. Dynamic Changes in the MicroRNA Expression Profile Reveal Multiple Regulatory Mechanisms in the Spinal Nerve Ligation Model of Neuropathic Pain. PLoS ONE. 2011; 6:e17670. [PubMed: 21423802]

Transl Res. Author manuscript; available in PMC 2016 January 01. 
[222]. Zhang HY, Zheng SJ, Zhao JH, Zhao W, Zheng LF, Zhao D, et al. MicroRNAs 144, 145, and 214 are down-regulated in primary neurons responding to sciatic nerve transection. Brain Res. 2011; 1383:62-70. [PubMed: 21276775]

[223]. Sakai A, Saitow F, Miyake N, Miyake K, Shimada T, Suzuki H. miR-7a alleviates the maintenance of neuropathic pain through regulation of neuronal excitability. Brain. 2013; 136:2738-50. [PubMed: 23861446]

[224]. Li X, Kroin JS, Kc R, Gibson G, Chen D, Corbett GT, et al. Altered Spinal MicroRNA-146a and the MicroRNA-183 Cluster Contribute to Osteoarthritic Pain in Knee Joints. J Bone Mineral Res. 2013; 28:2512-22.

[225]. Ni J, Gao Y, Gong S, Guo S, Hisamitsu T, Jiang X. Regulation of $\mu$-opioid type 1 receptors by microRNA134 in dorsal root ganglion neurons following peripheral inflammation. Eur J Pain. 2013; 17:313-23. [PubMed: 22865422]

[226]. Li H, Huang Y, Ma C, Yu X, Zhang Z, Shen L. MiR-203 Involves in Neuropathic Pain Development and Represses Rap1a Expression in Nerve Growth Factor Differentiated Neuronal PC12 Cells. Clin J Pain. 2014; 20:20.

[227]. Willemen H, Huo X-J, Mao-Ying Q-L, Zijlstra J, Heijnen C, Kavelaars A. MicroRNA-124 as a novel treatment for persistent hyperalgesia. J Neuroinflamm. 2012; 9:143.

[228]. Imai S, Saeki M, Yanase M, Horiuchi H, Abe M, Narita M, et al. Change in microRNAs associated with neuronal adaptive responses in the nucleus accumbens under neuropathic pain. $\mathrm{J}$ Neurosci. 2011; 31:15294-9. [PubMed: 22031875]

[229]. Sun Y, Li XQ, Sahbaie P, Shi XY, Li WW, Liang DY, et al. miR-203 regulates nociceptive sensitization after incision by controlling phospholipase A2 activating protein expression. Anesthesiology. 2012; 117:626-38. [PubMed: 22846677]

[230]. Zhou Q, Souba WW, Croce CM, Verne GN. MicroRNA-29a regulates intestinal membrane permeability in patients with irritable bowel syndrome. Gut. 2010; 59:775-84. [PubMed: 19951903]

[231]. Sakai A, Suzuki H. Nerve injury-induced upregulation of miR-21 in the primary sensory neurons contributes to neuropathic pain in rats. Biochem Biophys Res Commun. 2013; 435:17681. [PubMed: 23665014]

[232]. Shi G, Shi J, Liu K, Liu N, Wang Y, Fu Z, et al. Increased miR-195 aggravates neuropathic pain by inhibiting autophagy following peripheral nerve injury. Glia. 2013; 61:504-12. [PubMed: 23361941]

[233]. Bali KK, Selvaraj D, Satagopam VP, Lu J, Schneider R, Kuner R. Genome-wide identification and functional analyses of microRNA signatures associated with cancer pain. EMBO Mol Med. 2013; 5:1740-58. [PubMed: 24039159]

[234]. Genda Y, Arai M, Ishikawa M, Tanaka S, Okabe T, Sakamoto A. microRNA changes in the dorsal horn of the spinal cord of rats with chronic constriction injury: A TaqMan(R) Low Density Array study. Int J Mol Med. 2013; 31:129-37. [PubMed: 23124577]

[235]. Hori Y, Goto G, Arai-Iwasaki M, Ishikawa M, Sakamoto A. Differential expression of rat hippocampal microRNAs in two rat models of chronic pain. Int J Mol Med. 2013; 32:1287-92. [PubMed: 24065306]

[236]. Arai M, Genda Y, Ishikawa M, Shunsuke T, Okabe T, Sakamoto A. The miRNA and mRNA Changes in Rat Hippocampi after Chronic Constriction Injury. Pain Med. 2013; 14:720-9. [PubMed: 23461866]

[237]. Favereaux A, Thoumine O, Bouali-Benazzouz R, Roques V, Papon MA, Salam SA, et al. Bidirectional integrative regulation of Cav1.2 calcium channel by microRNA miR-103: role in pain. Embo J. 2011; 30:3830-41. [PubMed: 21804529]

[238]. Zhao J, Lee M-C, Momin A, Cendan C-M, Shepherd ST, Baker MD, et al. Small RNAs Control Sodium Channel Expression, Nociceptor Excitability, and Pain Thresholds. J Neurosci. 2010; 30:10860-71. [PubMed: 20702715]

[239]. Chen H-P, Zhou W, Kang L-M, Yan H, Zhang L, Xu B-H, et al. Intrathecal miR-96 Inhibits Nav1.3 Expression and Alleviates Neuropathic Pain in Rat Following Chronic Construction Injury. Neurochem Res. 2014; 39:76-83. [PubMed: 24234845] 
[240]. Kynast KL, Russe OQ, Moser CV, Geisslinger G, Niederberger E. Modulation of central nervous system-specific microRNA-124a alters the inflammatory response in the formalin test in mice. Pain. 2013; 154:368-76. [PubMed: 23318130]

[241]. Wang L, Chopp M, Szalad A, Zhang Y, Wang X, Zhang RL, et al. The role of miR-146a in dorsal root ganglia neurons of experimental diabetic peripheral neuropathy. Neuroscience. 2014; 259:155-63. [PubMed: 24316060]

[242]. Zhao X, Tang Z, Zhang H, Atianjoh FE, Zhao JY, Liang L, et al. A long noncoding RNA contributes to neuropathic pain by silencing Kcna2 in primary afferent neurons. Nat Neurosci. 2013; 16:1024-31. [PubMed: 23792947]

[243]. Mummaneni P, Shord SS. Epigenetics and Oncology. Pharmacotherapy. 2014 Published on-line March 11, 2014.

[244]. Bali KK, Hackenberg M, Lubin A, Kuner R, Devor M. Sources of individual variability: miRNAs that predispose to neuropathic pain identified using genome-wide sequencing. Mol Pain. 2014; 10:22. [PubMed: 24642266] 


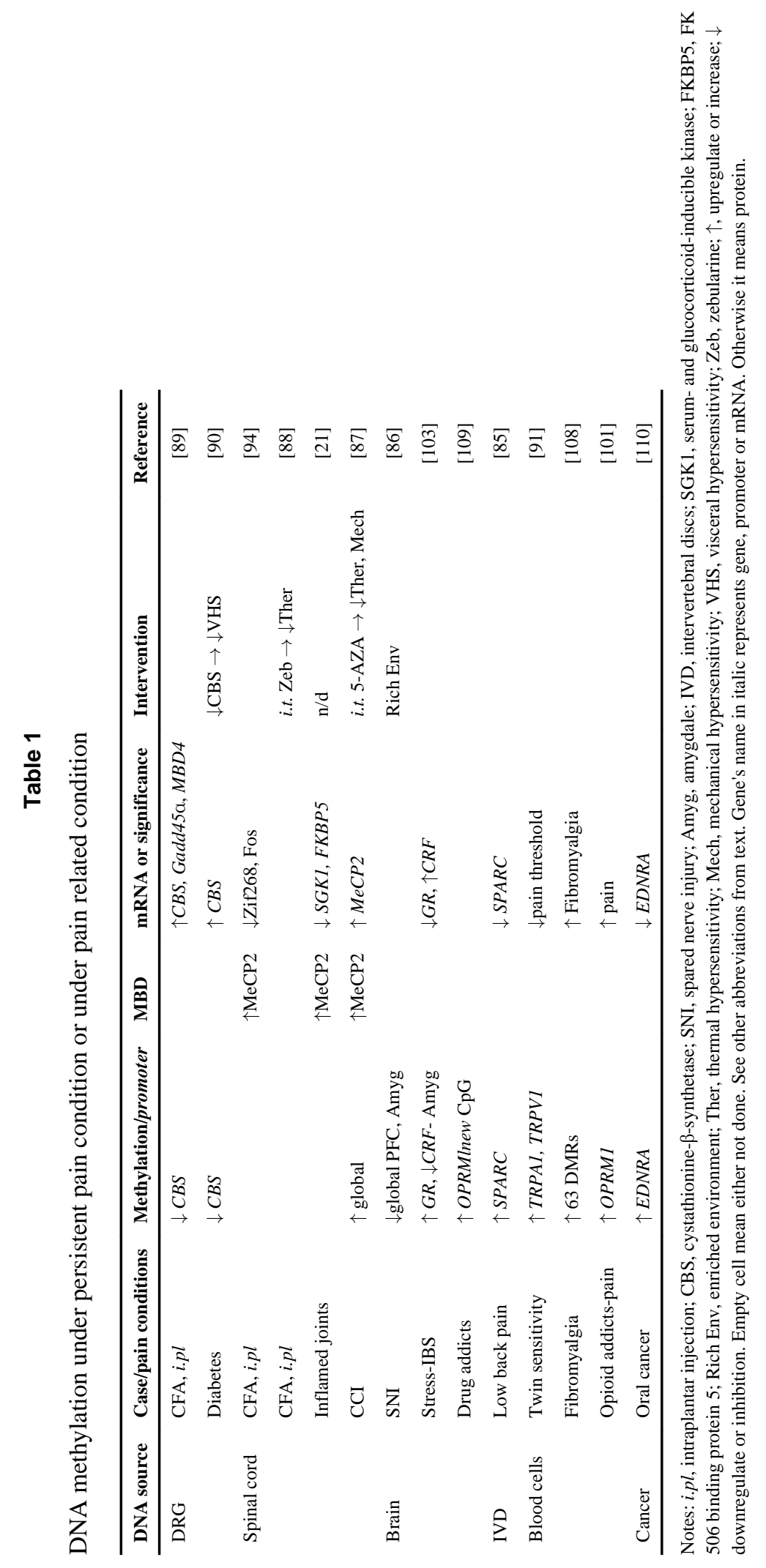

Transl Res. Author manuscript; available in PMC 2016 January 01. 


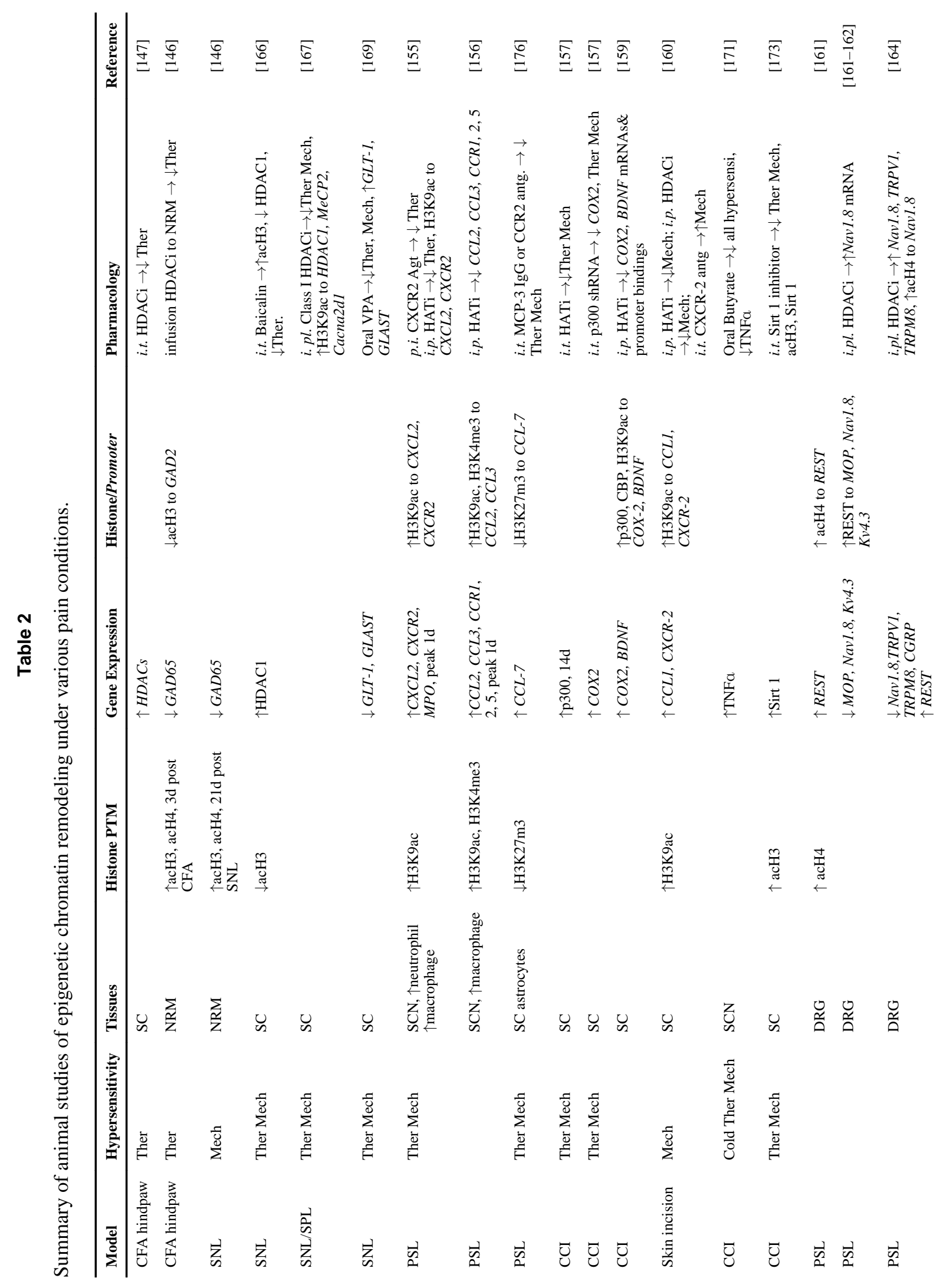




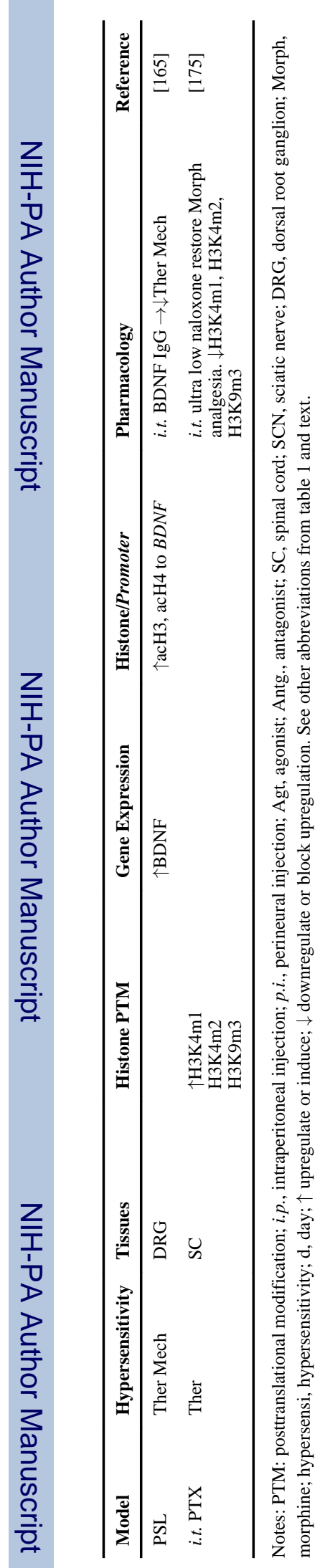


